\title{
La Terza macro fase
}

Prof. Giovanni DI TRAPANI

Dott.ssa Sara DIAMARE

\section{L'elaborazione dei dati raccolti}

\section{Profilo socio-demografico}

La popolazione in studio è costituita da circa $180.000^{10}$ professionisti iscritti agli Ordini TSRM e PSTRP. Nel mese di aprile sono state intervistate 14.086, selezionate con campionamento casuale ed intervistate a mezzo della somministrazione di un questionario (CAWI). I professionisti sanitari hanno partecipato in modo disomogeneo alla somministrazione in particolare nella tabella successiva è indicata la numerosità dei rispondenti suddivisi per Figura professionale

Tabella 2- Numerosità complessiva degli Intervistati (per Professione)

\begin{tabular}{|l|r|}
\hline $\begin{array}{l}\text { Figura professionale afferente l'Ordine TSRM e PSTRP } \\
\text { (DM 13/03/2018) }\end{array}$ & Intervistati \\
\hline Assistente Sanitario & 224 \\
\hline Dietista & 523 \\
\hline Educatore Professionale & 892 \\
\hline Elenco Speciale & 53 \\
\hline Fisioterapista & 5.092 \\
\hline Igienista Dentale & 960 \\
\hline Logopedista & 1.198 \\
\hline Ortottista e Assistente di Oftalmologia & 262 \\
\hline Podologo & 254 \\
\hline Tecnico Audiometrista & 61 \\
\hline Tecnico Audioprotesista & 263 \\
\hline Tecnico della Prevenzione nell'Ambiente e nei Luoghi di Lavoro & 535 \\
\hline Tecnico della Riabilitazione Psichiatrica & 230 \\
\hline Tecnico di Neurofisiopatologia & 239 \\
\hline Tecnico Fisiopatologia Cardiocircolatoria e Perfusione Cardiovascolare & 123 \\
\hline Tecnico Ortopedico & 91 \\
\hline Tecnico Sanitario di Laboratorio Biomedico & 1.179 \\
\hline Tecnico Sanitario di Radiologia Medica & 1.195 \\
\hline Terapista della Neuro e Psicomotricità dell'Età Evolutiva & 482 \\
\hline Terapista Occupazionale & 174 \\
\hline (vuoto) & 56 \\
\hline Totale complessivo & $\mathbf{1 4 . 0 8 6}$ \\
\hline
\end{tabular}

\footnotetext{
${ }^{10}$ Si veda La Federazione degli Ordine TSRM PSTRP L'Universo di Riferimento dell'indagine
} 
Il tasso di risposta, proprio per il metodo utilizzato è risultato molto elevato e pari al 99,61 \%, il tasso di rifiuto del $0,39 \%$.

\section{Le caratteristiche demografiche degli intervistati}

Di seguito, si riportano l'elaborazione dei dati raccolti dalla somministrazione del questionario; in particolare in questa sezione del lavoro tratteremo delle caratteristiche demografiche degli intervistati relativamente all'età, al sesso, il titolo di studio degli intervistati, ma anche un'analisi del contesto familiare. Per una più approfondita analisi, il presente lavoro ha inteso condurre un ulteriore approfondimento circa l'andamento demografico con particolare riferimento all'età degli operatori e dei professionisti afferenti agli Ordini TSRM e PSTRP.

\section{L'età e ill sesso}

Uomini e donne non sono egualmente rappresentati $(32,52 \%$ e $67,48 \%)$.

Figura 9 - La rappresentatività per diversità di genere

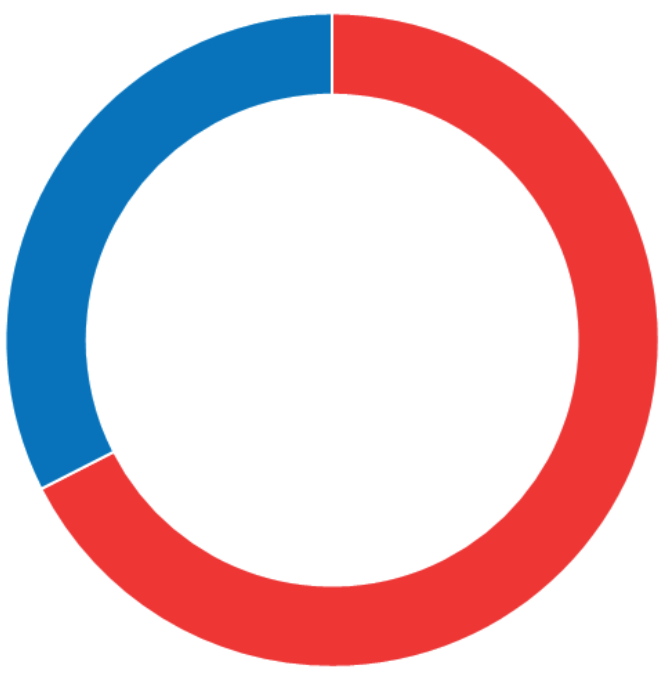

- Femmina

Maschio

Nostra Elaborazione

Il campione è risultato costituito per il $37,03 \%$ da professionisti tra i $18-34$ anni, il $35,32 \%$ da professionisti tra i 35-49 anni, il 22,15\% da professionisti tra i 50-59 anni, il 5,37\% da professionisti tra i 60-69; solo 19 sono gli over 69.

La distribuzione per sesso e classi di età del campione è sovrapponibile a quella della popolazione di riferimento, indice di una buona rappresentatività del campione selezionato. L'età media è risultata di 41,69 anni per gli uomini e di 40,44 anni per le donne. 
Il titolo di studio

Tra 18 e 69 anni si stima che solo lo $0,15 \%$ dei professionisti abbia la licenza media, il 5,72\% il Diploma o la Maturità, il 80,68\% la Laurea (Triennale o Magistrale), infine il $13,44 \%$ è in possesso di un titolo Post Laurea (Dottorato, Specializzazione postLaurea, Master). Non si osservano differenze significative per sesso, la distribuzione segue la proporzione tra $\mathrm{i}$ sessi.

Come atteso, l'istruzione è fortemente etàdipendente: gli anziani mostrano livelli di istruzione significativamente più bassi rispetto ai più giovani. Eventuali confronti di altre variabili per il titolo di studio devono quindi tener conto dell'effetto dell'età.

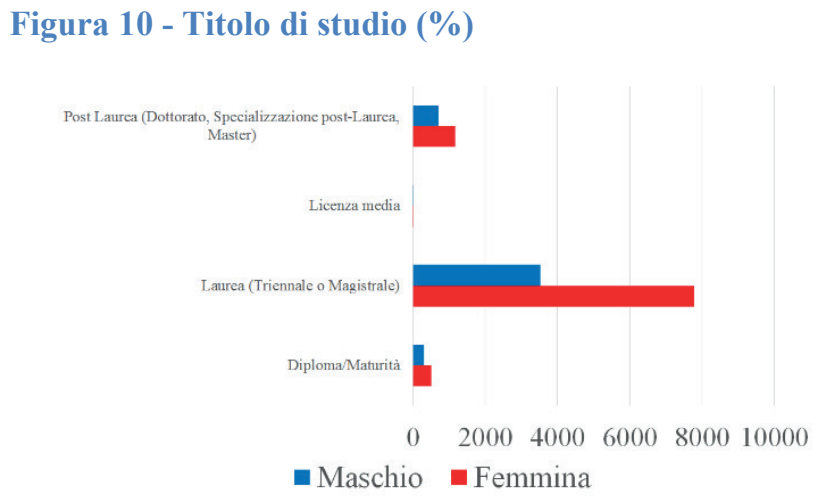
Figura 11 - Scolarità media* per classi di età
(valori in percentuale)

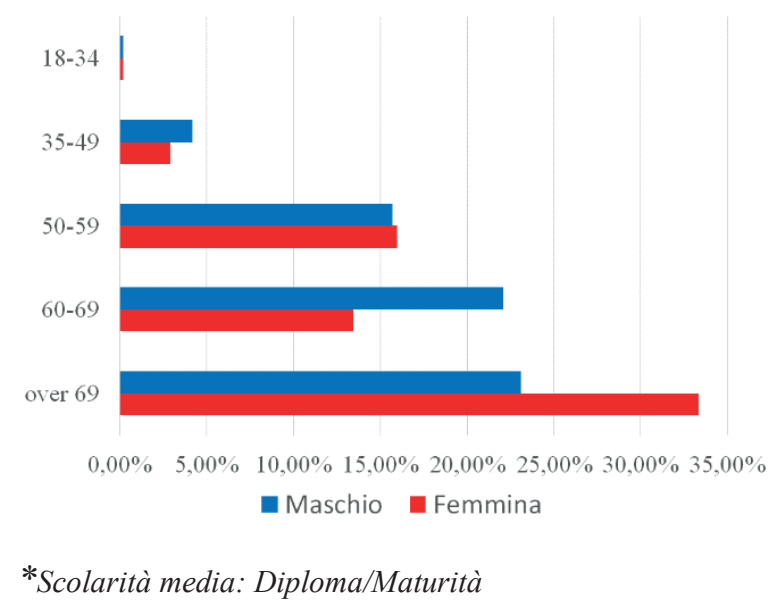

\section{Il contesto familiare}

Si stima che il $43,17 \%$ dei professionisti afferenti gli Ordini TSRM e PSTRP siano coniugati, il $20,49 \%$ abbia una relazione basata sulla convivenza; poco meno del $5 \%$ siano separati o divorziati e solo lo $0,48 \%$ sia in stato di vedovanza. Il restante $30 \%$ è equamente diviso tra chi è Single e chi invece è Fidanzata/o. 
Figura 12 - Stato Relazionale dei Professionisti per Classi di Età (valori percentuale)
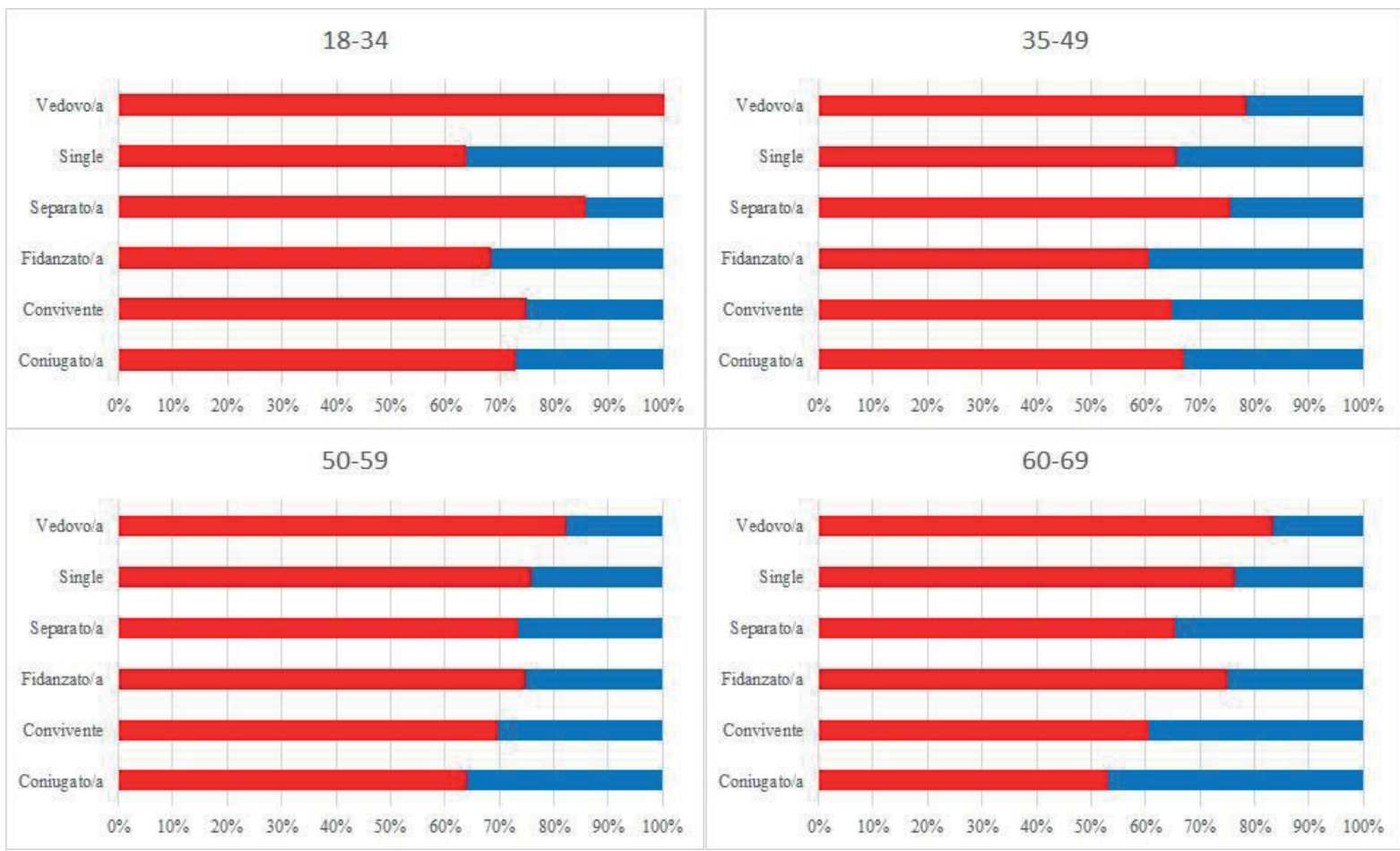

Nostra Elaborazione

Per concludere questo breve excursus sul profilo Socio demografico dei professionisti TSRM e PSTRP, si stima che il 51\% NON ha figli, del restante $49 \%$ possiamo altresì ipotizzare che poco meno del $40 \%$ abbia un solo figlio ed il $60,67 \%$ ne abbia più di uno. (Figura $\mathrm{X}$ )

Figura 13 - Numerosità del Campione (Items Figli a carico)

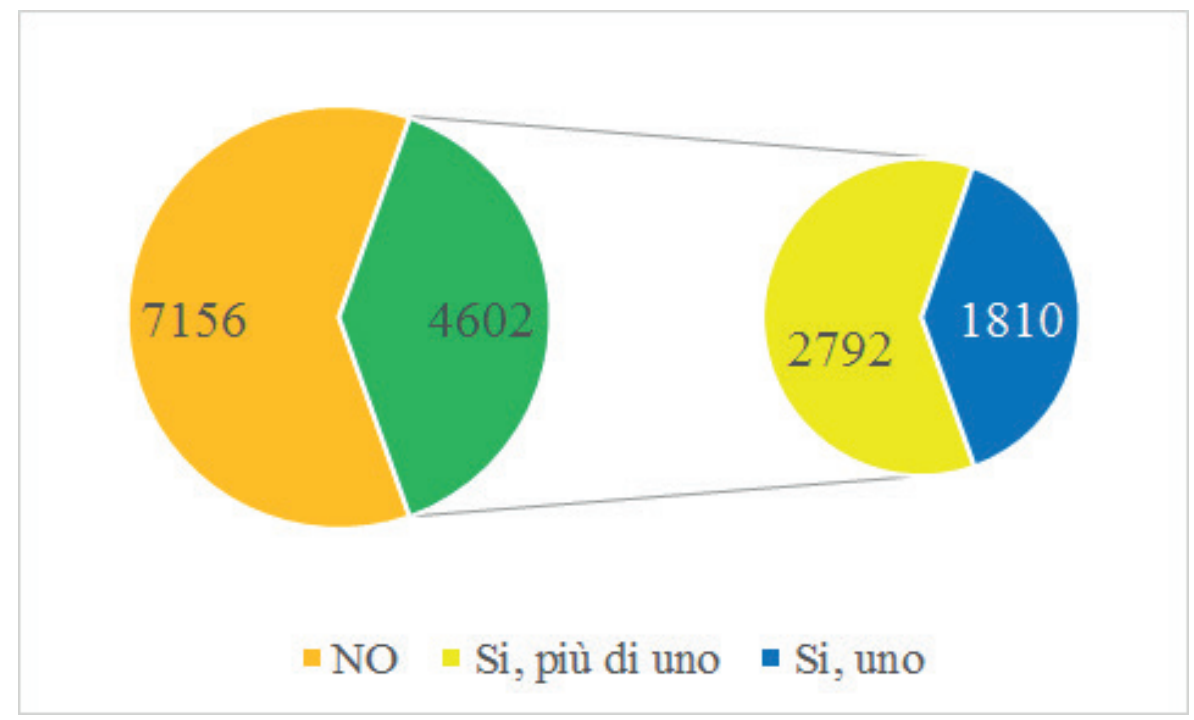

Nostra Elaborazione 


\section{L'andamento demografico}

Per una più approfondita analisi dell'età degli operatori e dei professionisti afferenti agli Ordini TSRM e PSTRP si è scelto di procedere impiegando uno strumento che la prassi scientifica adopera per la disciplina della statistica demografica: le piramidi della popolazione. Tale strumento consente di analizzare e rappresentare al meglio la distribuzione per età che è stata raggruppata per fasce quinquennali $(20-24 ; 25-29 ; 30-34$ ecc).

Si precisa, al fine della piena intelligibilità delle rappresentazioni grafiche espresse nella Figura 14 che in ascissa è indicato l'ammontare degli operatori e professionisti TSRM e PSTRP per ciascuna classe di età (in unità); tale valore stato riprodotto una volta in senso ordinario (crescente verso destra) e una volta nel senso opposto (crescente verso sinistra) in modo da distinguere i due sessi (maschi e femmine). Lo studio delle piramidi d'età ha lo scopo di meglio analizzare la struttura demografica della Federazione Nazionale degli Ordini TSRM e PSTRP. È opportuno precisare che le 19 figure professionali sono state raggruppate per Aree precisamente: Prevenzione, Riabilitativa e Tecnica (Assistenziale e Diagnostica).

Figura 14 - Le piramidi d'età - per raggruppamenti d'Area delle Figure professionali

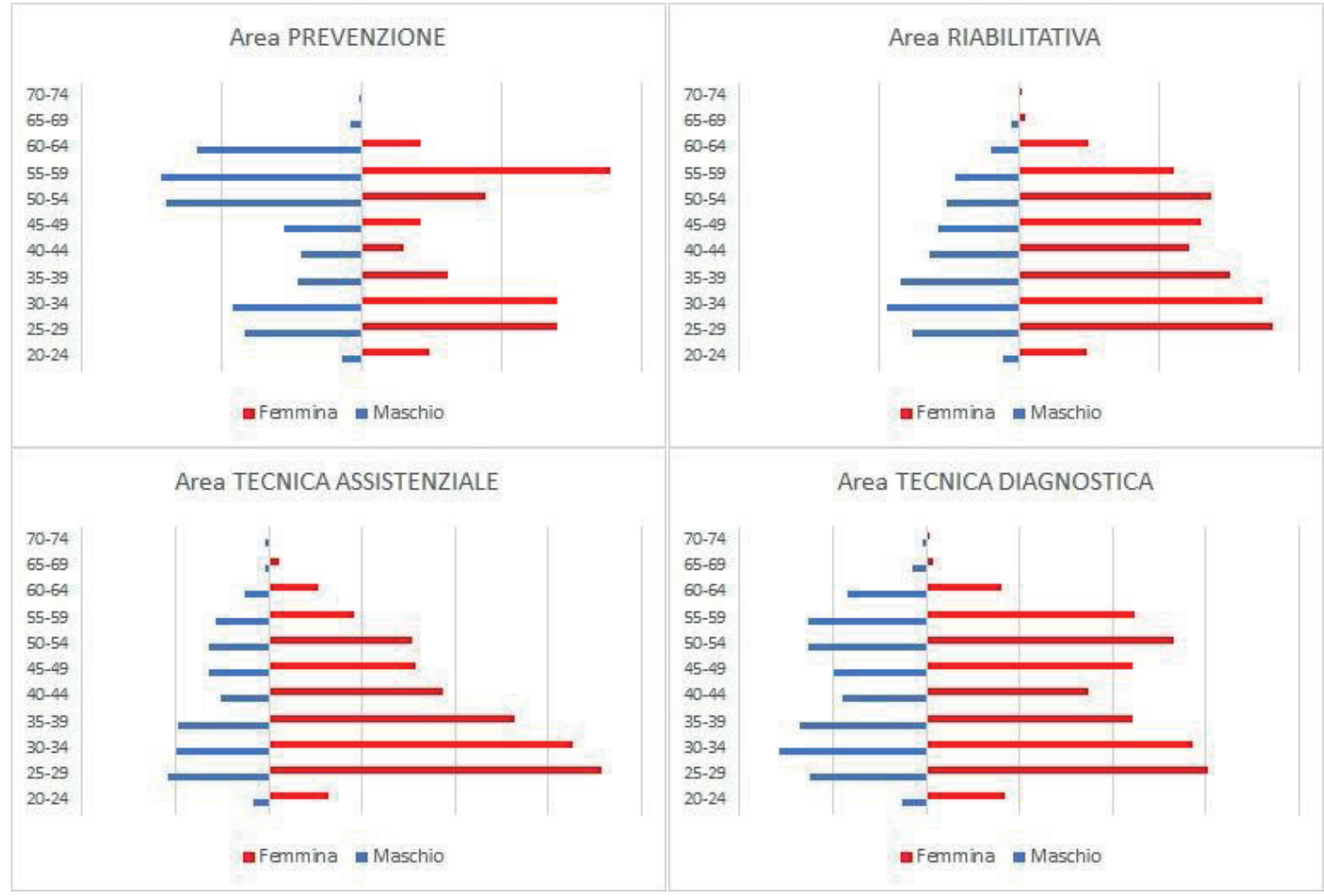

Nostra elaborazione 
Le diverse forme dei grafici poco prima rappresentati dipendono, come già affermato, proprio dalla struttura demografica degli Ordini TSRM e PSTRP. Per tutte e quattro i raggruppamenti, infatti, si può apprezzare un'ampia struttura demografica con prevalenza del genere femminile ed una numerosità bassa della fascia d'età 20-24. Quest'ultima affermazione può essere legata ai requisiti d'accesso agli Ordini che richiedo un grado di scolarizzazione elevato; legato, infatti, al conseguimento di una laurea. Inoltre, è possibile affermare che l'area della Prevenzione presentando una distribuzione a clessidra sotto intende due concentrazioni e precisamente nelle fasce d'età over 50 e under 30 . Ciò può dipendere da un rinnovato appeal delle professioni dell'area della Prevenzione nelle fasce più giovani. Comunque, la numerosità di certo ampia per le fasce più giovani dei professionisti TSRM e PSTRP consente di fare previsioni più che favorevoli circa la prospettiva di una piena vitalità degli Ordini e naturalmente di queste figure professionali.

Figura 15 - La piramide d'età per i professionisti dell'Elenco speciale

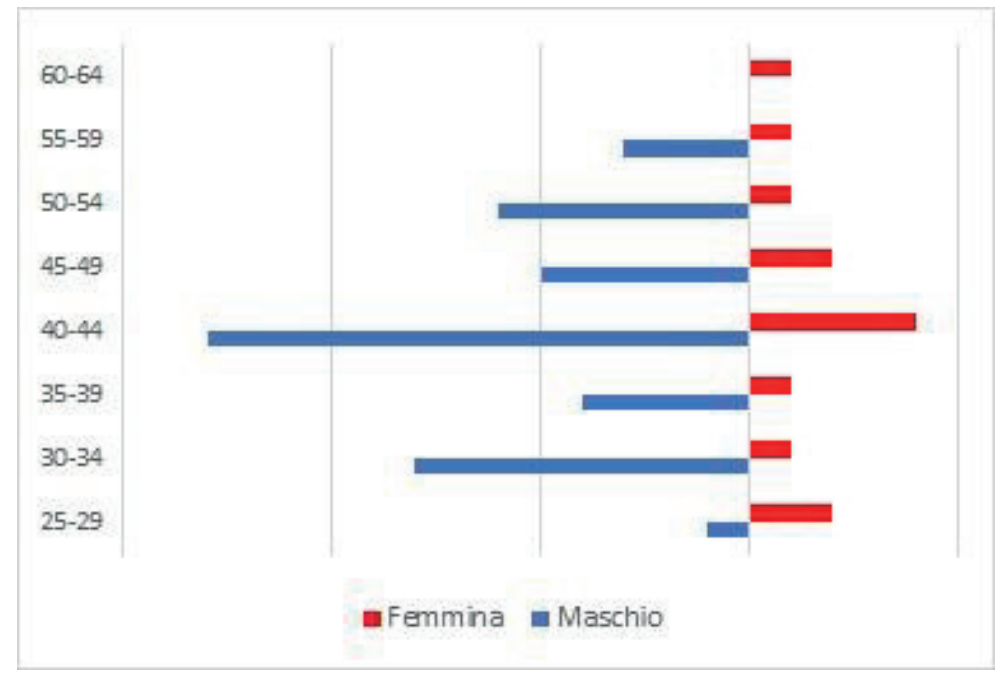

Nostra Elaborazione

Per quanto attiene, invece, il così detto Elenco Speciale (Figura 15), prima di tutto è opportuno chiarire che il range delle fasce d'età non è omogeneo con quelle delle altre Aree delle Figure professionali. È possibile stimare, infatti, una numerosità di gran lunga inferiore alle omologhe professioni, mancando - in termini quantitativi - i soggetti over 65. Inoltre, a differenza delle altre aree, l'Elenco speciale presenta una ulteriore difformità almeno in relazione alla differenza di genere. È, infatti, certamente maggiore la numerosità dei professionisti di sesso maschile, e di questi è possibile stimarne una maggior concentrazione nella fascia d'età dei 40enni. 
Possiamo, in conclusione, affermare che la vitalità in termini di prospettiva futura dell'Elenco speciale segna certamente una tendenza marcatamente differente le altre Aree professionali questo a causa della numerosità molto più bassa delle fasce più giovani di tali professionisti.

\section{Informazioni lavorative}

Per quanto attiene alla sezione "Informazioni lavorative", con la somministrazione del questionario in pieno periodo di quarantena ed emergenza sanitaria si è inteso individuare le ricadute in termini occupazionale e le modificazioni del comportamento dei professionisti in relazione alla propria attività lavorativa che, come sappiamo, ha avuto effetti dissimili tra le eterogenee figure professionali. Le attività lavorative dei TSRM e PSTRP hanno subito modificazioni profonde, in alcuni casi perché "indotte" dai DPCM ed in altri casi a causa di scelte liberamente intraprese dai professionisti sanitari. Tale affermazione trova riscontro, naturalmente, nella profonda eterogenia delle 19 professioni, in quanto solo alcune tipologie di professionisti sono impegnati in attività lavorative alle dipendenze di strutture pubbliche o private, mentre, in altri casi, questi sono invece titolari di studi o di centri.

I DPCM che si sono susseguiti nel corso del tempo hanno avuto un notevole impatto sul tutto il tessuto socioeconomico del paese e, come già brevemente affermato, anche i professionisti TSRM e PSTRP sono stati pienamente coinvolti dall'ondata, o forse meglio dallo tsunami denominato COVID-19. A causa delle profonde differenze che le figure professionali presentano, al fine di omogeneizzare il flusso informativo dei dati provenienti dalla somministrazione del questionario, si è provveduto - come espresso nella 
Tabella 3 - Le Aree delle Figure Professionali TSRM e PSTRP

\begin{tabular}{|c|c|}
\hline AREE & Figure Professionali \\
\hline \multirow{8}{*}{$\begin{array}{c}\text { Area professioni sanitarie } \\
\text { riabilitative }\end{array}$} & Fisioterapista \\
\hline & Logopedista \\
\hline & Podologo \\
\hline & Ortottista \\
\hline & Terapista della neuro psicomotricità dell' età evolutiva \\
\hline & Tecnico della riabilitazione psichiatrica \\
\hline & Terapista occupazionale \\
\hline & Educatore professionale \\
\hline \multirow{2}{*}{$\begin{array}{l}\text { Area professioni-tecniche } \\
\text { della prevenzione }\end{array}$} & Assistente sanitario \\
\hline & Tecnico della prevenzione nell'ambiente e luoghi di lavoro \\
\hline \multirow{4}{*}{ Area tecnico-diagnostica } & Tecnico audiometrista \\
\hline & Tecnico sanitario di laboratorio biomedico \\
\hline & Tecnico sanitario di radiologia medica \\
\hline & Tecnico di neurofisiopatologia \\
\hline \multirow{5}{*}{ Area tecnico-assistenziale } & Tecnico audioprotesista \\
\hline & Tecnico ortopedico \\
\hline & Dietista \\
\hline & Tecnico perfusionista \\
\hline & Igienista dentale \\
\hline
\end{tabular}

Questa suddivisione è alla base delle successive analisi; tra le aree delle figure professionali afferenti i TSRM e PSRTP, che nella Figura X sono espresse in termini percentuali, quella Riabilitativa è quella che presenta la maggiore numerosità seguita dai Tecnici Diagnostici, dai Tecnici Assistenziali seguiti dai professionisti dell'area della Prevenzione. Numerosità di certo degna di nota benché in termini quantitativa molto minore è quella dei professionisti dell'Elenco Speciale che ricordiamo è ad esaurimento. 
Figura 16 - Le Aree delle Figure Professionali TSRM e PSTRP

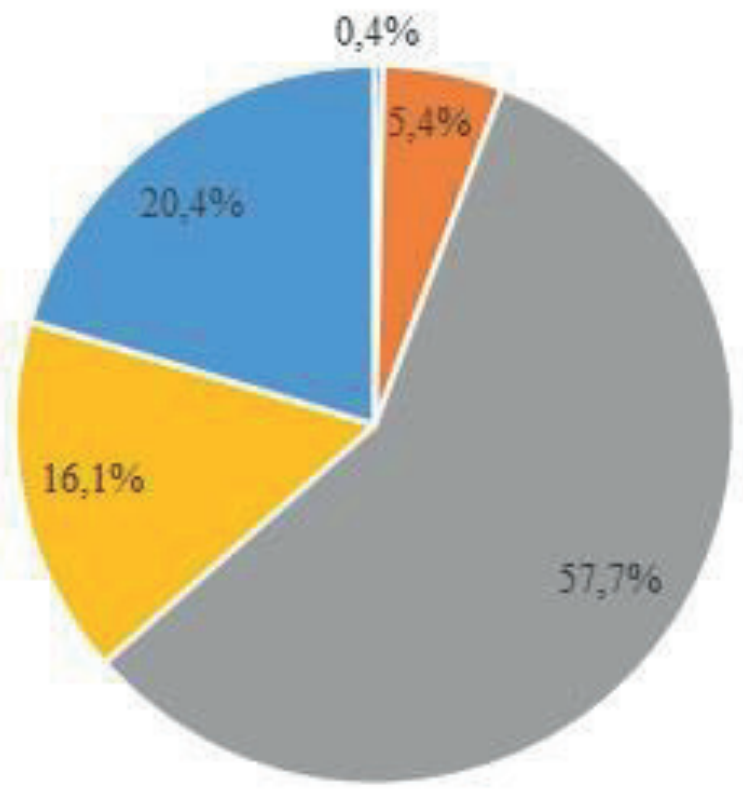

- Elenco Speciale

- Prevenzione

- Riabilitativa

- Tecnica Assistenziale

- Tecnica Diagnostica

Le aree rispecchiano fedelmente la composizione numerica della Federazione Nazionale degli Ordini TSRM e PSTRP, e, pertanto, il campionamento realizzato trova ulteriore dimostrazione del carattere informativo derivante dai dati oggetto dell'analisi condotta nel presente lavoro; in relazione alle Figure professionali, di seguito è esposta una rappresentazione quantitativa della numerosità di risposte fornite dai professionisti afferenti le 19 figure professionali (Figura 17).

Figura 17 - Le Figure Professionali TSRM e PSTRP

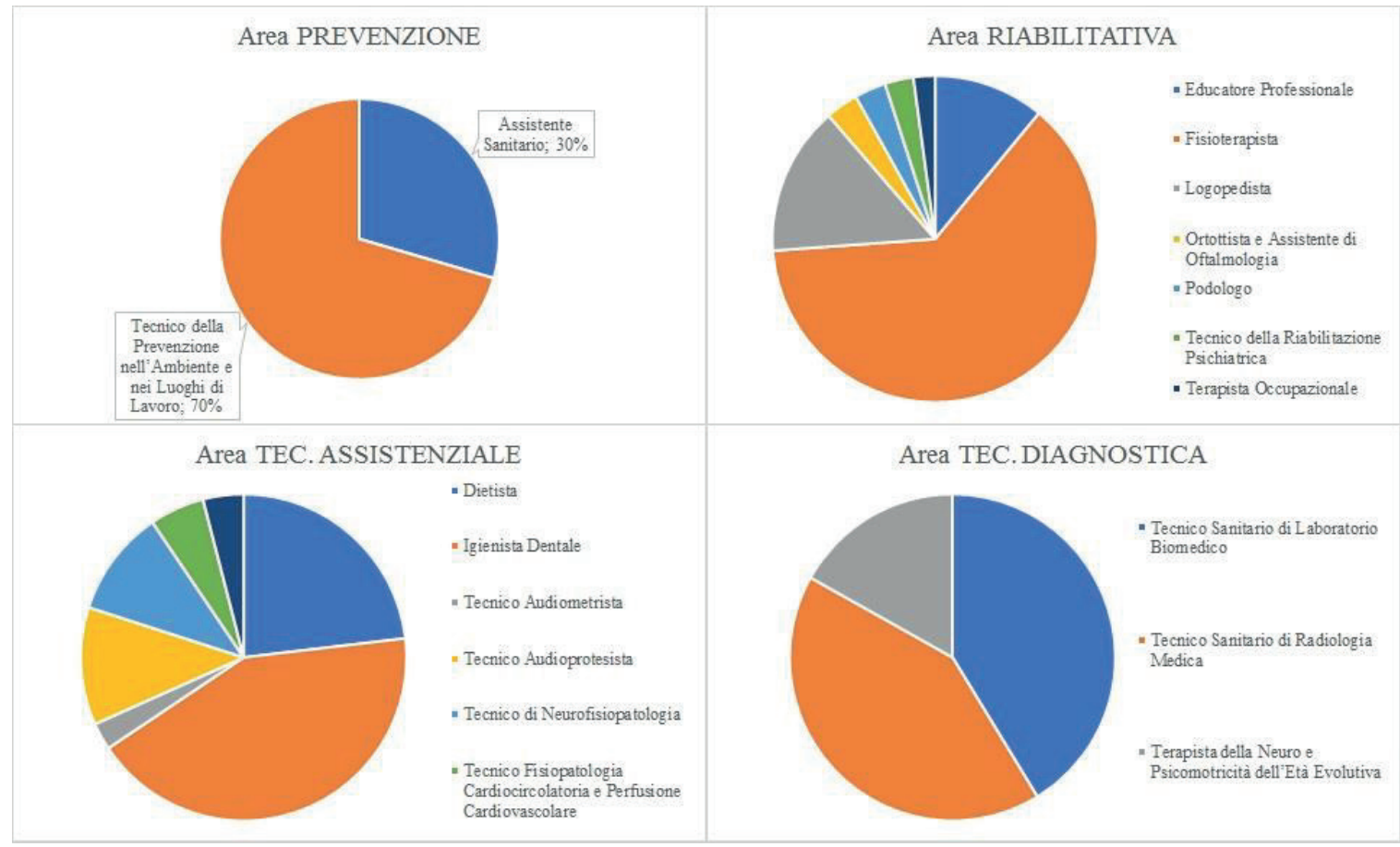


In relazione all'Area Prevenzione, è possibile notare una numerosità molto superiore dei Tecnici della Prevenzione nell'Ambiente e nei Luoghi di Lavoro rispetto agli Assistenti Sanitari; infatti i primi possiamo stimarli nel 70,49\%. Per quanto riguarda l'area Riabilitativa la numerosità maggiore di risposte proviene dai Fisioterapisti ( $63 \%$ circa), degno di ulteriore nota è il numero di risposte pervenute dai Logopedisti che rappresentano il $14,79 \%$ del totale; di poco inferiore l'apporto quantitativo degli Educatori Professionali (11\%). Le risposte degli altri professionisti si attestano in valori molto minori e comunque al di sotto del $3 \%$.

L'Area Tecnica, come già ribadito, è suddivisa in Area Tecnica Assistenziale e Diagnostica; la prima annovera la maggior numerosità di risposte da parte degli Igienisti dentali $(42,48 \%)$, seguono $\mathrm{i}$ Dietisti con il 23\% del totale. I tecnici di Neurofisiopatologia e gli Audioprotesista rappresentano rispettivamente il 10 e l' $11 \%$ delle risposte; tutti gli altri professionisti si assestano su valori inferiori al 6\%. Dell'Area Tecnica Diagnostica di rilievo - almeno in termini quantitativi - sono le risposte pervenute dai Tecnici Sanitari di Laboratorio Biomedico e quelli afferenti alla Radiologia Medica, entrambi con poco più del $40 \%$ di risposte. I Terapista della Neuro e Psicomotricità dell'Età Evolutiva, in ultimo, rappresentano poco meno del 17\% delle risposte pervenute ed afferenti all'Area Tecnica Diagnostica.

\section{Posizione Lavorativa}

Come ampiamente ribadito nelle precedenti parti del presente lavoro, l'indagine ha voluto comprendere ed analizzare l'impatto del COVID- 19 sugli operatori e professionisti TSRM e PSTRP. Dall'indagine condotta a mezzo del questionario in prima analisi ci si è concentrati sulle modifiche sui processi lavorativi che il virus e principalmente i DPCM hanno avuto sui professionisti sanitari. La crisi sanitaria, con lo strumento normativo adottato dei successivi decreti del Presidente del Consiglio dei Ministri ed il così detto Lock-Down, ha comportato un radicale stravolgimento del mondo del lavoro. Il Governo, infatti, ha introdotto forme di contenimento della diffusione del virus adottando strumenti di distanziamento sociale e chiudendo molte attività produttive. Scelte politiche certamente non facili che presentano ricadute in termini economiche enormi dettate dal Comitato di Sicurezza Nazionale e supportate dall'azione della Protezione Civile che hanno, tra l'altro, avuto ricadute importanti anche sul mondo del lavoro. Si sono infatti adottate anche policies di ammortizzazione sociale per sgravare in qualche modo le imprese dei costi del personale e per garantire così il permanere delle forme di una redditività per i lavoratori. Nel Sistema dei TSRM e PSTRP il COVID-19 le differenti modalità di svolgimento del lavoro dei professionisti hanno avuto gravi ricadute; molti dei quali, infatti, sono stati collocati in Cassa Integrazione Straordinaria o si sono visti costretti a chiudere la propria attività. A dirla tutta, però, la chiusura delle attività produttiva non sempre è stata una diretta conseguenza dei DPCM, ma - come già sostenuto in altre parti del 
presente lavoro - si è dimostrata essere una scelta mossa dal senso di responsabilità dei professionisti TSRM e PSTRP nei riguardi dei propri assistiti e comunque dell'intera popolazione.

È innanzitutto importante evidenziare che non tutti i professionisti hanno cosi subito misure restrittive almeno riguardo la propria attività lavorativa; possiamo stimare, infatti, che più del $52 \%$ dei TSRM e PSTRP siano regolarmente rimasti in servizio ed in piena attività lavorativa (Figura 18).

Figura 18 - I professionisti TSRM e PSTRP (attivi e non in attività)

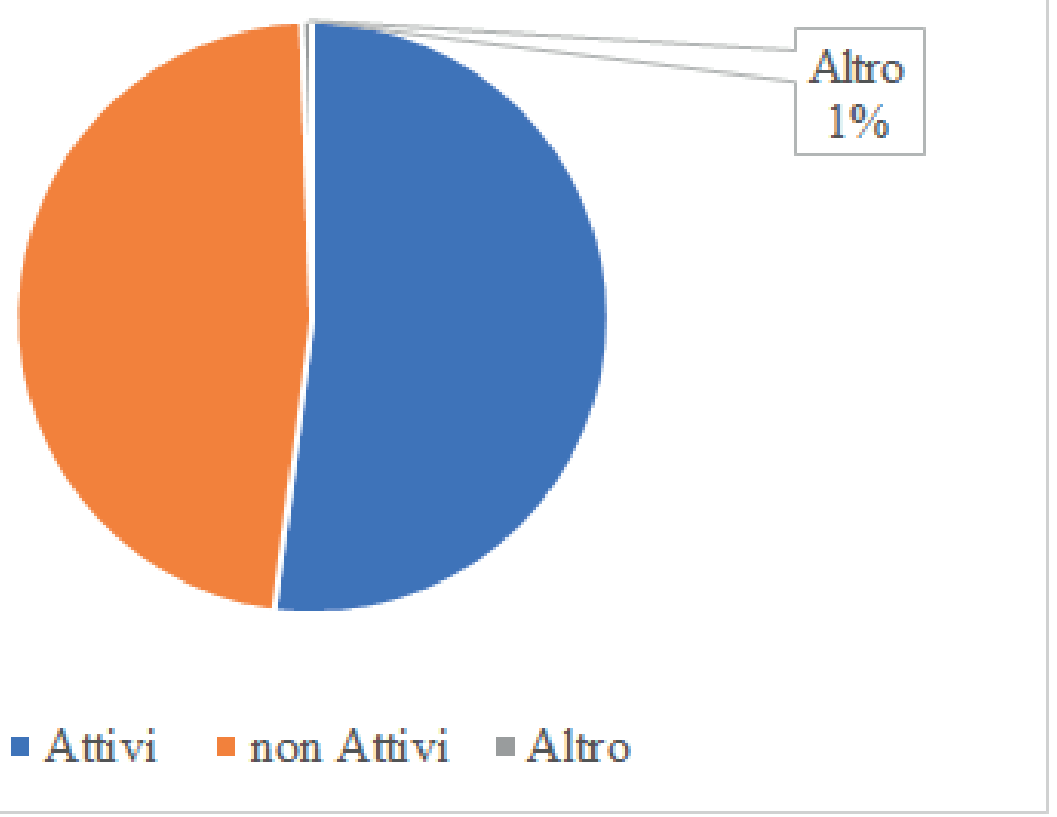

L'eterogenia anche nelle modalità di svolgimento del proprio lavoro da parte dei professionisti sanitari, ha comportato, vedremo più avanti, impatti differenziati figura per figura. Possiamo così stimare che le modificazioni dei processi di lavoro hanno riguardato principalmente le figure professionali afferenti all'Elenco speciale, infatti, 1'85\% di questi ha visto cambiare profondamente il proprio processo lavorativo; seguono i professionisti dell'area Tecnica Assistenziale e quelli dell'area Riabilitativa. Le figure professionali afferenti alle aree Tecnica Diagnostica e della Prevenzione sono quelli che hanno subito minori modificazioni.

Nella Figura X sono riportati in valore percentuale le differenti opzioni delle modificazioni dei processi lavorativi per i TSRM e PSTRP non in attività, quali la cassa integrazione, i permessi e la chiusura delle attività. Per meglio comprendere, quindi, le differenti opzioni di cambiamento dei processi lavorativi, si sono rappresentati graficamente i professionisti (sempre classificati per aree) partendo in primis dall'Elenco Speciale per poi esporli, seguendo quanto poco prima affermato, in relazione alla maggiore numerosità delle tipologie di professionisti resi inattivi dal COVID-19. 
Figura 19 - Le modificazioni dei processi lavorativi a seguito delle misure di contenimento del COVID-19.

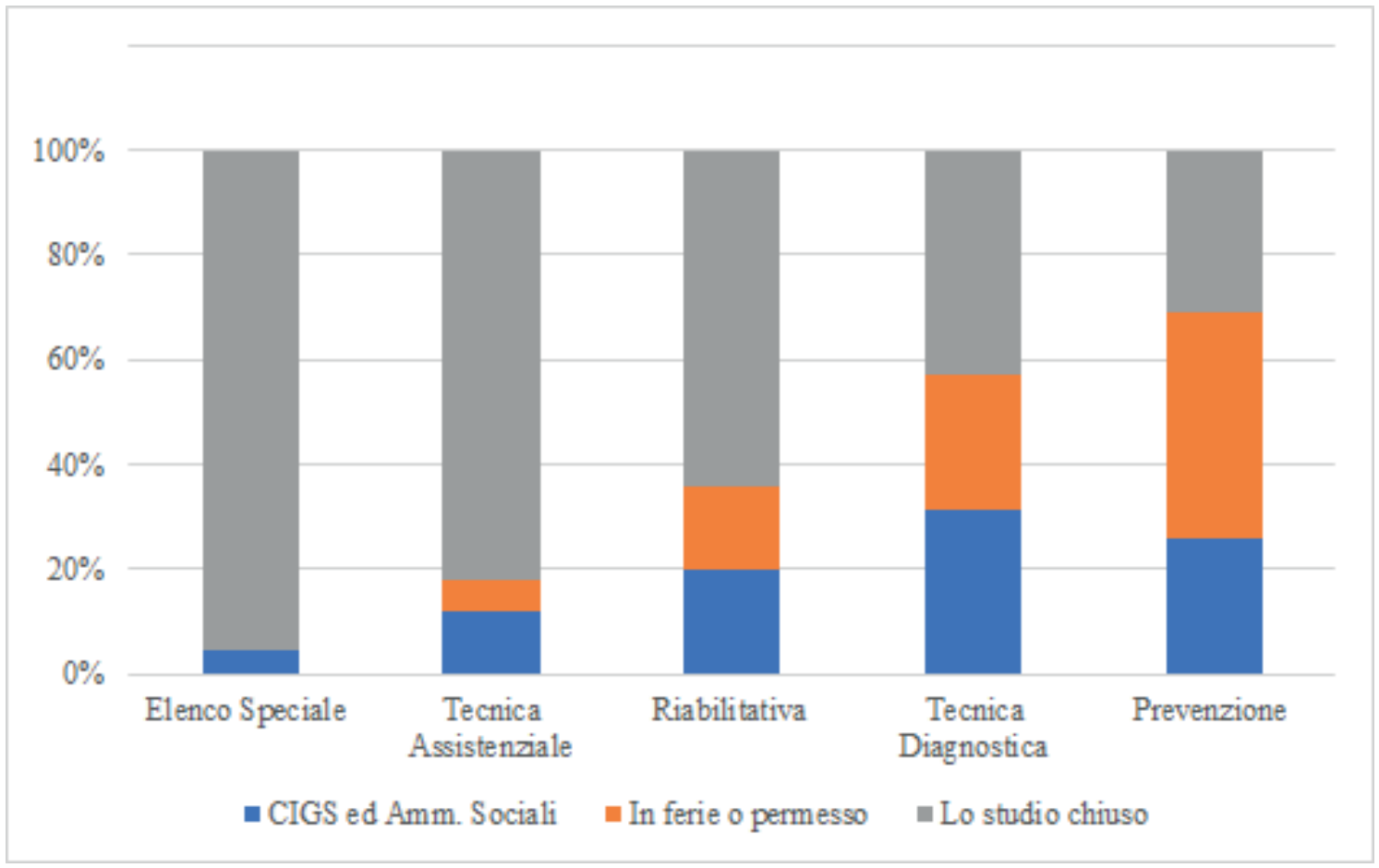

È evidente, allora, una non omogena distribuzione delle differenti cause di non attività del TSRM e PSTRP; ragioni differenti legate, come detto, dalle diverse modalità di svolgimento del lavoro per le 19 figure professionali e dei professionisti dell'Elenco Speciale. Tra tutte, la chiusura dello studio è la causa maggiore, solo i professionisti dell'area della Prevenzione annoverano come ragione di inattività il collocamento in ferie o la richiesta di permessi.

Se la chiusura dello studio è, come affermato, il motivo della maggior inattività tra le aree, questa non ha certamente la stessa distribuzione tra le figure professionali; possiamo, infatti, stimare che siano i Fisioterapisti i professionisti che nel periodo della crisi sanitaria hanno avuto l'attività non operativa, seguiti poi dagli Igienisti Dentali e dai Logopedisti. Tra quelli che, invece, seppur hanno avuto lo studio chiuso, hanno risentito in modo nettamente inferiore delle modificazioni susseguenti la crisi sanitaria, troviamo gli Assistenti Sanitari. Nell'Area della Prevenzione sono, invece, i Tecnici della Prevenzione nell'Ambiente e nei Luoghi di Lavoro i professionisti che hanno come motivo di inattività la chiusura dello studio; nell'area Riabilitativa, invece, si stima che siano i Fisioterapisti ad aver chiuso lo studio maggiormente. Per le aree Tecniche sono gli Igienisti Dentali ed i Terapisti della Neuro e Psicomotricità dell'Età Evolutiva a contare in termini percentuali la chiusura dello studio come causa dell'inattività lavorativa.

Infine, tra le altre cause di inattività, è la Cassa integrazione Straordinaria e le altre forme di ammortizzazione sociale che si stima abbia coinvolto maggiormente i Tecnici della Prevenzione 
nell'Ambiente e nei Luoghi di Lavoro, seguiti dai Fisioterapista, dai Terapisti della Neuro e Psicomotricità dell'Età Evolutiva e dai Tecnici Audioprotesisti.

\section{Sicurezza sul lavoro}

Per quanto attiene una prima valutazione dell'impatto del Covid-19 sui professionisti afferenti agli Ordini TSRM PSTRP, il questionario poneva domande specifiche sulla sicurezza riscontrata sui luoghi di lavoro. Come primo elemento da porre in evidenza è stato quello di conoscere se nelle settimane di piena emergenza sanitaria i professionisti TSRM e PSTRP fossero stati direttamente impegnati con pazienti COVID.

Dai dati raccolti con la somministrazione del questionario emerge un pieno coinvolgimento dei professionisti con pazienti COVID-19; infatti, più del 73\% dei professionisti dichiarano che nel pieno dell'emergenza sanitaria sono stati direttamente impegnati con pazienti colpiti dal virus.

Tenendo in debita considerazione l'eterogenia delle attività lavorative prestate dai professionisti TSRM e PSTRP, dalle risposte fornite possiamo affermare che, tra tutti, i professionisti afferenti all'area Riabilitativa (42,46 \%) sono quelli che hanno avuto, in piena emergenza sanitaria, un contatto maggiore con i pazienti COVID-19, seguiti dai professionisti dell'area tecnica della Diagnostica (41,38 \%). Meno del dieci percento dei professionisti della Prevenzione e dell'area tecnica Assistenziale, invece, dichiarano rispettivamente di aver avuto contatto cin pazienti affetti da Virus.

Di seguito riportiamo, i grafici (istogrammi) inerenti alla numerosità delle risposte pervenute dai professionisti - suddivise per Aree - che hanno avuto un contatto con i pazienti affetti dal Virus. Come evidenziato dalla Figura XX, tra i professionisti dell'area Riabilitativa, sono i Fisioterapisti quelli che presentano valori maggiori (72\%). 
Figura 20 - Numerosità delle risposte pervenute dai professionisti dell'Area Riabilitativa

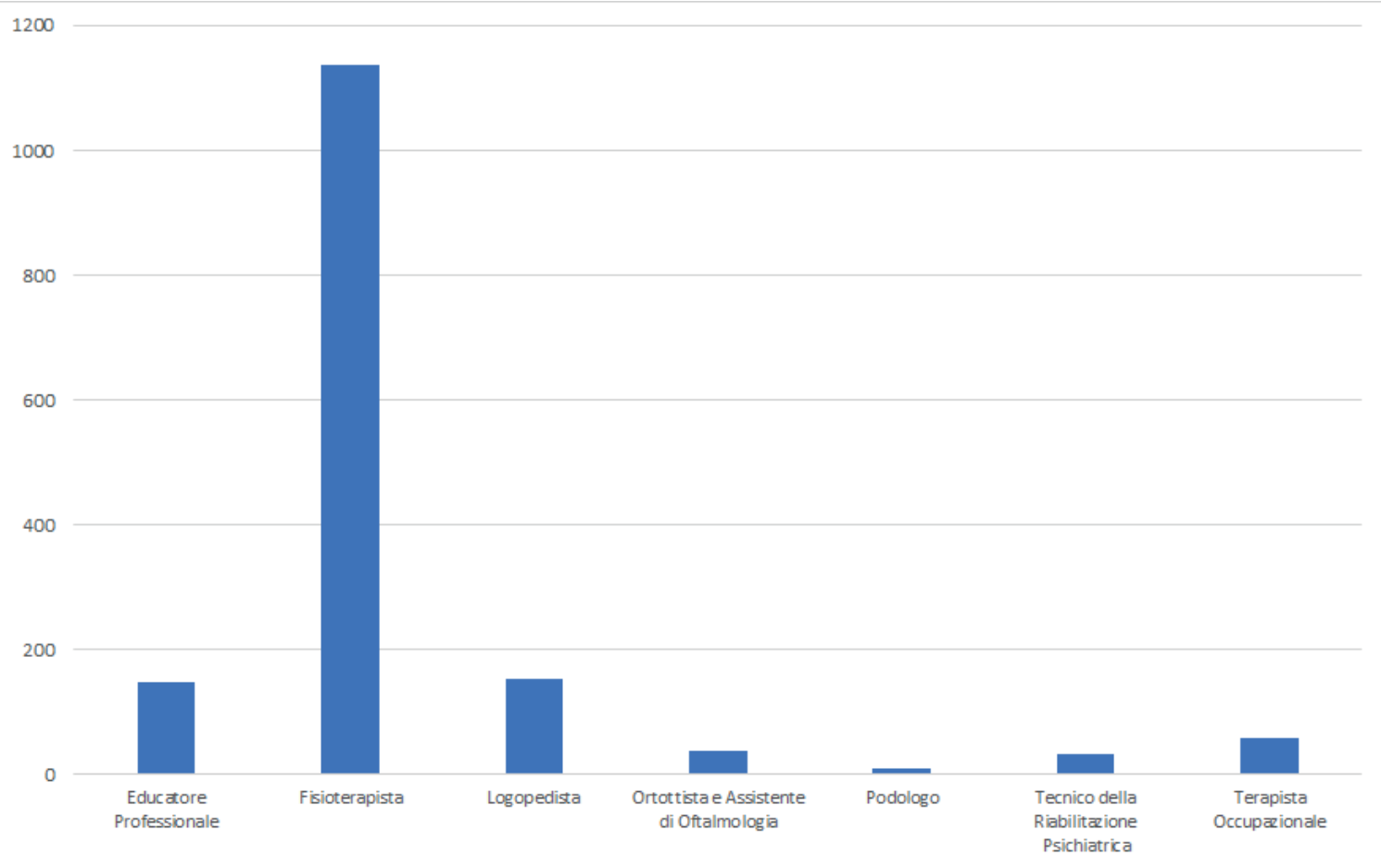

Tra i Professionisti dell'Area tecnica della Diagnostica, invece, dalla figura XXX è agevole notare che sono i Tecnici Sanitari di Radiologia Medica quelli che dichiarano un contatto maggiore con pazienti affetti dal virus (55\%) seguiti dai Tecnici Sanitari di Laboratorio Biomedico.

Figura 21 - Numerosità delle risposte pervenute dai professionisti dell’Area tecnica della Diagnostica

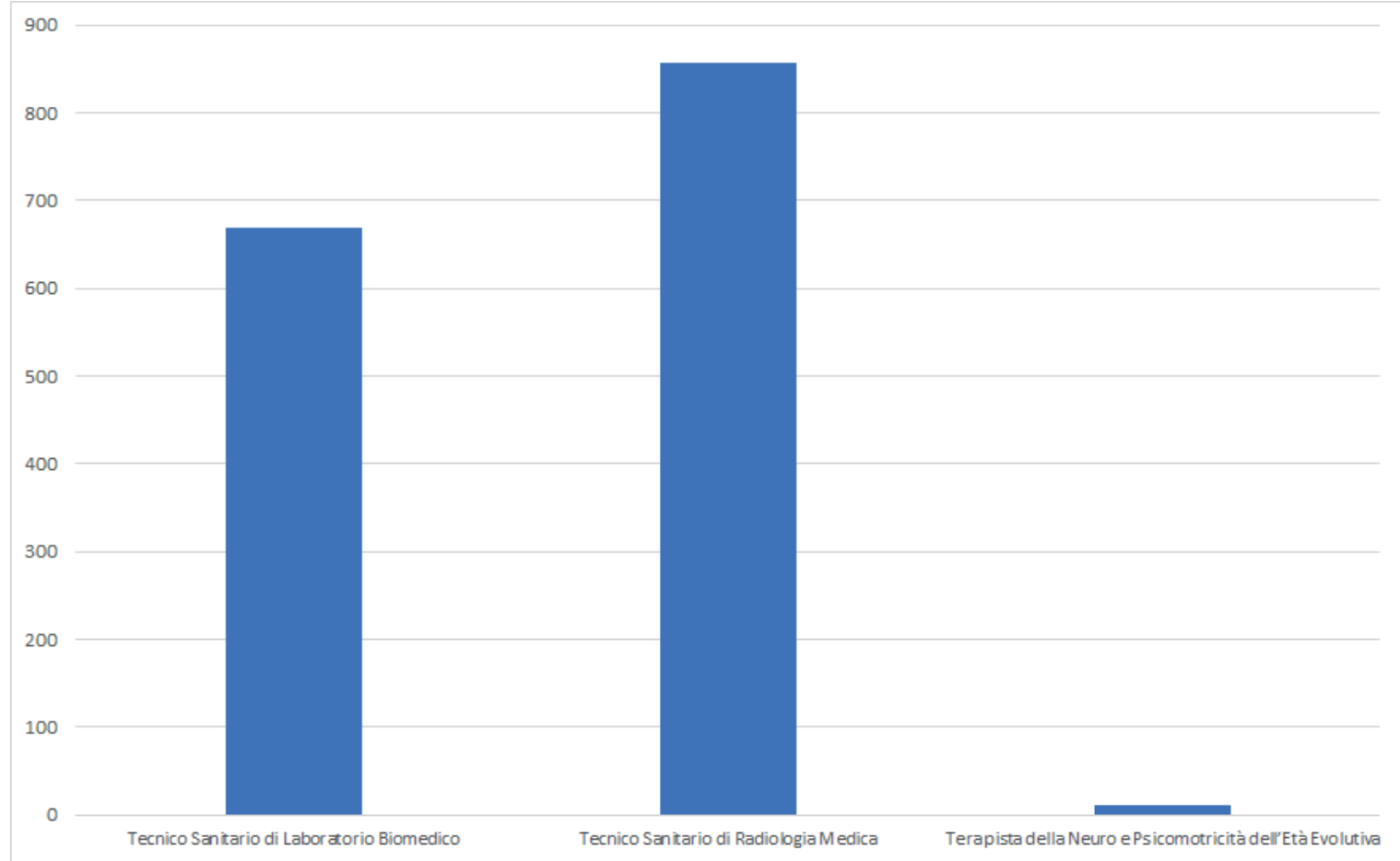


Per quanto riguarda, poi, l'area tecnica assistenziale, i Tecnici di Neurofisiopatologia sono quelli che dichiarano un maggior contatto con pazienti COVID-19.

I professionisti afferenti all'Ordine TSRM e PSTRP hanno, quindi, avuto un'elevata esposizione ed un forte contatto con i pazienti affetti dal Virus, come del resto tutte le professioni sanitarie, una situazione che ha avuto effetti anche sullo stato di salute dei professionisti, infatti, poco meno di mille intervistati dichiarano di essere in isolamento o addirittura ricoverati.

\section{I dispositivi di Sicurezza}

Sono un numero davvero cospicuo gli intervistati che hanno dichiarato che nel pieno di emergenza sanitaria si trovavano regolarmente in servizio (93\%), e pertanto, una valutazione circa la presenza o meno di DPI (dispositivi di Sicurezza) assume un rilevante carattere di importanza soprattutto in materia di scurezza sul lavoro. Dalle risposte pervenute, fortunatamente più della metà degli intervistati ha dichiarato di essere stato in possesso di dispositivi di sicurezza; tra questi, il 55,46\% sono professionisti dell'area Riabilitativa, 23,80\% dell'area Tecnica della Diagnostica e il 13,67\% dell'area tecnica Assistenziale. Infine, solo 6,50\% dei professionisti della Prevenzione dichiara di essere stato in possesso di dispostivi di sicurezza.

Tenendo in considerazione che i professionisti TRSM e PSTRM possono svolgere la loro attività sia in ambito pubblico che in ambito provato, è da rilevare che i DPI sono solo per il $43 \%$ degli intervistati resi disponibili dalle strutture pubbliche. Analizzando, quindi, la disponibilità di mascherine per aree professionali distinte per ambito lavorativo (pubblico e privato), salta all'occhio che nel comparto pubblico i professionisti maggiormente esposti al rischio di contagio del virus per mancanza di dispostivi di sicurezza sono stati quelli dell'area della Riabilitazione e dell'area tecnica della Diagnostica.

L'esposizione al rischio contagio, però è da evidenziare, che non è stato molto percepito dai professionisti, in quanto, nelle strutture direttamente impegnati con pazienti COVID-19, il $60 \%$ degli intervistati, dichiara di essere stato dotati di DPI, cui, per dovere di cronaca, vanno sommati coloro i quali (poco più del 30\%) dichiarano che "Non sempre" sono risultati sprovvisti di dispostivi di sicurezza. 
La situazione nelle aree del paese maggiormente colpite dalla COVID-19.

Come purtroppo riportano le cronache e soprattutto i dati ufficiali della Protezione civile, il nostro Paese ha registrato in alcuni ambiti territoriali un'incidenza di gran lunga superiore rispetto la media nazionale, ci riferiamo, allora, ad alcuni comuni della bergamasca e comunque dell'intera regione della Lombardia.

Nella sola regione lombarda, la percentuale di professionisti che hanno dichiarato di essere stati dotati di dispositivi di sicurezza è pari al 58,51\% del totale (Figura 22).

Figura 22 - Percentuale di risposte pervenute sulla disponibilità di DPI dai professionisti della Regione Lombardia.

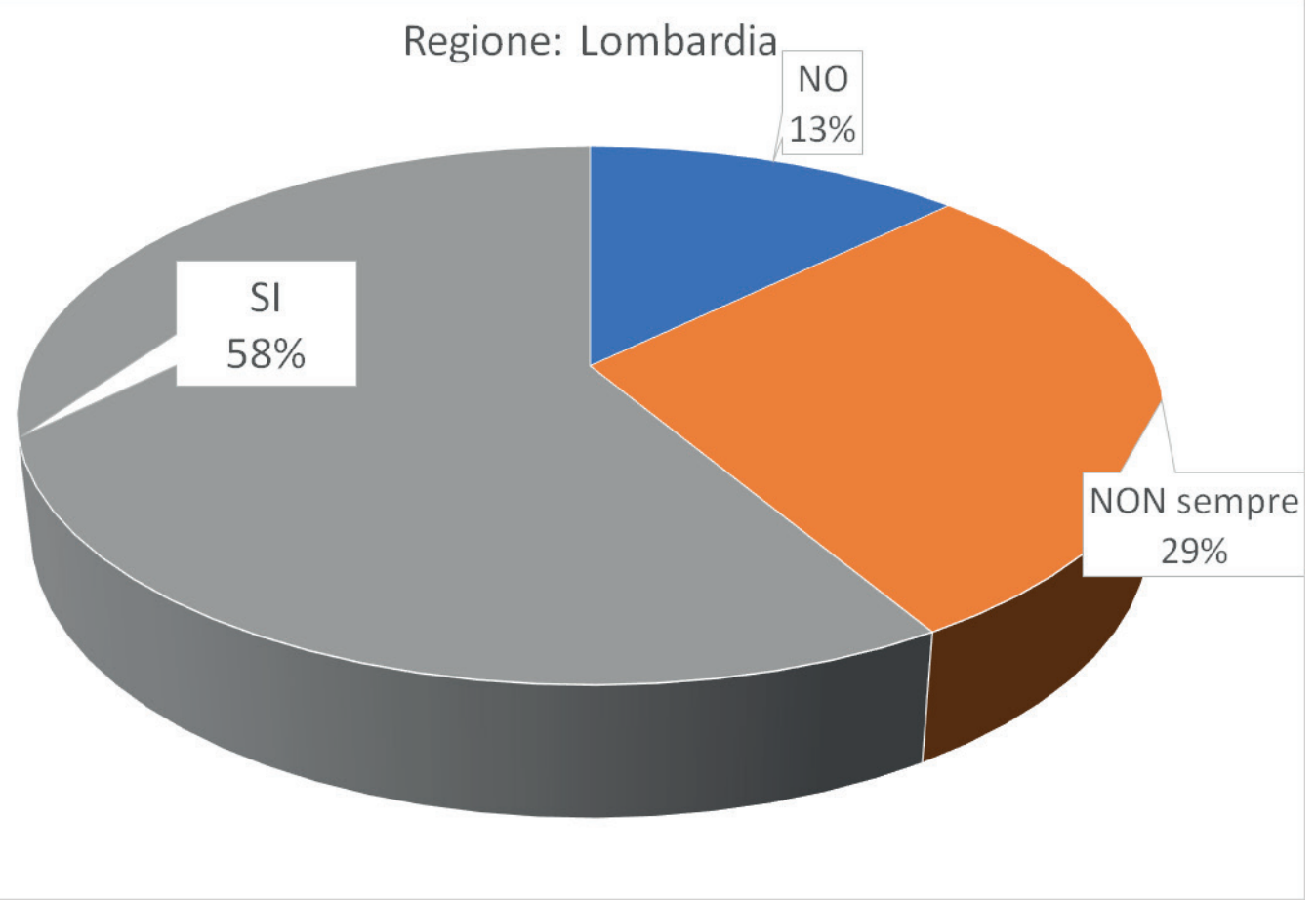

La percezione dell'esposizione al rischio di contagio del VIRUS.

Dalle risposte fornite dagli intervistati, è stato possibile, altresì, rilevare il grado di percezione dell'esposizione al rischio di contagio del VIRUS, che è stato misurato in correlando le risposte di coloro che non essendo dotati di dispositivi di sicurezza e che hanno regolarmente prestato la propria attività lavorativa.

Di questi professionisti, più del 58\% ritiene di essere stato esposto ad un rischio di contagio medio alto; in particolare di seguito riportiamo i valori espressi in percentuale regione per regione (Tabella 4): 
Tabella 4 - La percezione dell'esposizione al rischio di contagio per Regione

$\begin{array}{lllr}\text { Abruzzo } & 58,89 & \text { Molise } & 52,13 \\ \text { Basilicata } & 80,32 & \text { Piemonte } & 59,28 \\ \text { Calabria } & 65,01 & \text { Puglia } & 69,52 \\ \text { Campania } & 56,08 & \text { Sardegna } & 57,59 \\ \text { Emilia-Romagna } & 55,83 & \text { Sicilia } & 66,51 \\ \text { Friuli-Venezia Giulia } & 47,56 & \text { Toscana } & 54,62 \\ \text { Lazio } & 60,14 & \text { Trentino-Alto Adige } & 49,83 \\ \text { Liguria } & 66,90 & \text { Umbria } & 69,21 \\ \text { Lombardia } & 57,13 & \text { Valle d'Aosta } & 53,24 \\ \text { Marche } & 54,05 & \text { Veneto } & 55,32\end{array}$

Sull'argomento, ci riserviamo di fornire ulteriori informazioni grazie a successivi approfondimenti resi possibili dalla massiccia campagna di adesione allo screening (Follow Up) cui i professionisti hanno inteso di partecipare. 


\section{Impatto e Resilienza}

\section{La percezione dello stress e sulla resilienza dei professionisti afferenti agli Ordini TSRM PSTRP \\ di Sara DIAMARE}

Forniremo qui di seguito una prima valutazione dell'impatto del Covid-19 sulla percezione dello stress e sulla resilienza dei professionisti afferenti agli Ordini TSRM PSTRP. Nella sezione specifica del questionario che comprende le domande dalla 20 alla 24 è stato chiesto di rispondere a quesiti mirati per valutare l'impatto psicologico e le possibili forme di Resilienza attiva che i professionisti sanitari possono attuare per far fronte all'emergenza COVID-19.

Le risposte esaminate riguardano la percezione di utilità legata alla professione nel fronteggiare le attuali emergenze del Sistema Sanitario, l'interesse nello svolgere la propria attività lavorativa, la percezione del mondo ed altri eventi problematici che avrebbero potuto aggravare la sensazione di stress.

Per valutare l'impatto psicologico e la resilienza al COVID nelle diverse professionalità afferenti alle aree dell'Ordine TSRM PSTRP con l'esposizione al rischio di contagio, il contagio personale o di colleghi da COVID-19, si è proceduto alla disamina di dati disaggregati sia per professionalità, che per genere.

Tenere in considerazione il genere in relazione alla salute è considerato un aspetto necessario a garantire efficacia ed equità ai sistemi sanitari di ogni Paese: la "Global Health 50/50", un'organizzazione internazionale che promuove l'uguaglianza di genere nell'assistenza sanitaria, sta raccogliendo $\mathrm{i}$ dati disaggregati per sesso su COVID-19 disponibili pubblicamente. In Italia, fra l'altro, il 69\% degli operatori sanitari infetti è donna, anche se bisogna tener conto della più alta percentuale di donne in queste categorie professionali. In particolare, esamineremo le risposte alle domande 20-24 per valutare i vissuti disforici degli operatori TSRM PSTRP intervistati:

\section{Domanda n. 20 - Nel corso dell'emergenza, ritiene che la Sua professione sia stata utile per fronteggiare le nuove esigenze del Sistema Sanitario?}

La risposta generale al quesito è positiva nel $55.86 \%$ degli operatori. In particolare, si sono sentiti maggiormente utili i professionisti dell'area diagnostica e della prevenzione $(<80 \%)$ 
e dell'area riabilitativa $(<50 \%)$; quest'ultima percentuale, considerata la numerosità del campione intervistato incide sul totale complessivo.

Il maggior numero di professionisti che hanno avuto una percezione di esposizione al rischio medio-alto si sentono utili in questa situazione d'emergenza sanitaria.

Figura 23: percezione di utilità correlata all' esposizione al rischio

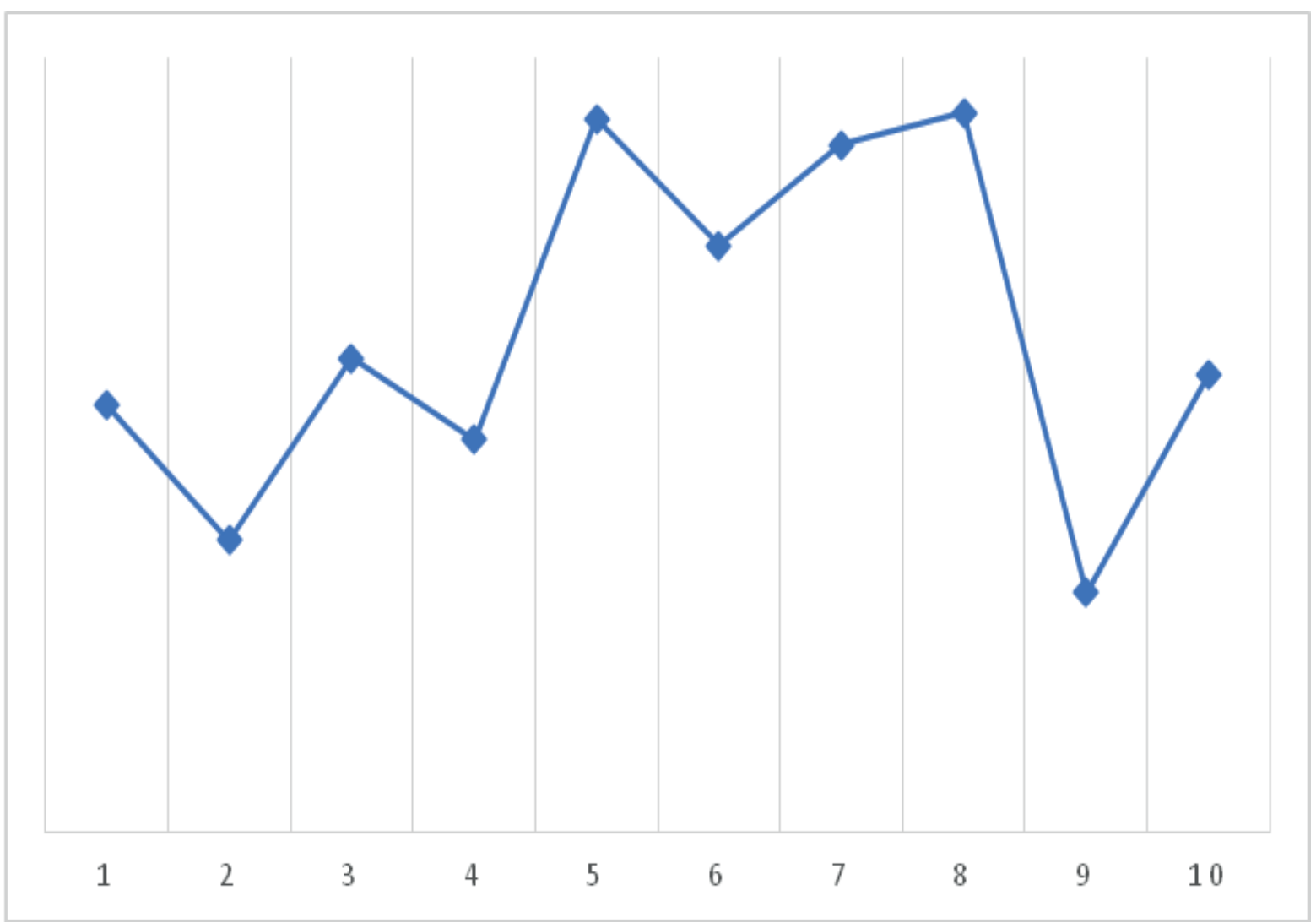

La maggior parte degli operatori contagiati percepisce l'utilità della propria professione (67.10\%). Anche i professionisti che hanno avuto colleghi (3.546/13.697 professionisti) contagiati o in quarantena hanno percepito fortemente la loro utilità (67.01\%).

Dall'analisi dei dai disaggregati per genere, risulta che gli uomini (61.09\%), rispetto alle donne $(53.32 \%)$, considerano la propria professione maggiormente utile per fronteggiare l'attuale emergenza sanitaria.

Considerato che il campione analizzato è composto da un numero di donne quasi il doppio di quello degli uomini le risposte negative delle donne $(71,27 \%)$ incidono sui risultati positivi totali $(55.86 \%)$. 
Domanda 21. Lei ha provato disinteresse o poco piacere nello svolgere la Sua attività lavorativa?

Il $78.62 \%$ degli operatori delle professioni sanitarie ha provato interesse per il proprio lavoro durante il periodo della pandemia.

Figura 24: disinteresse al lavoro durante il periodo della pandemia suddiviso per aree

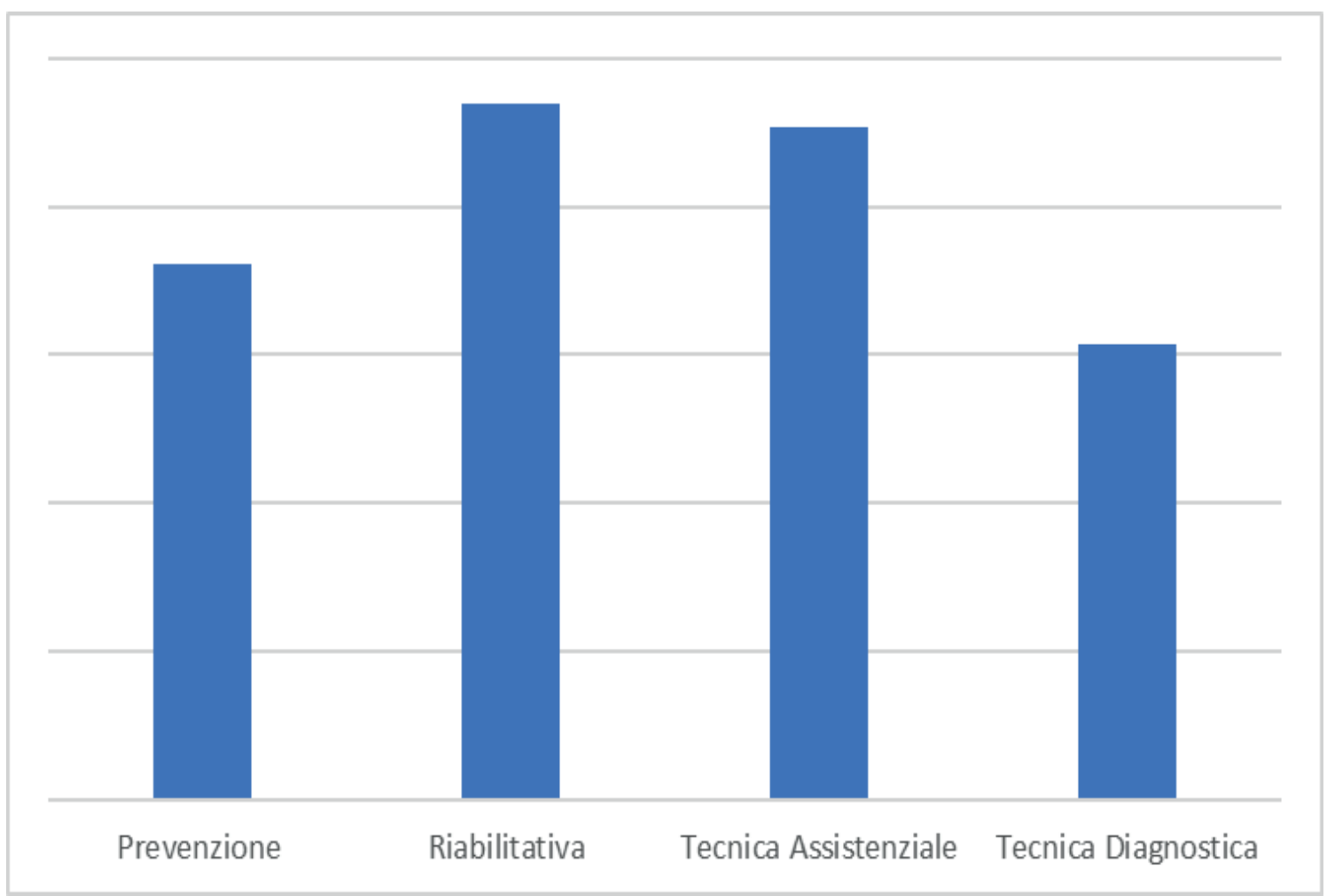

Gli uomini hanno dichiarato un interesse lievemente maggiore rispetto alla popolazione femminile e solo il $21,38 \%$ ha provato disinteresse nello svolgere la Sua attività lavorativa. In particolare il $23.49 \%$ dei professionisti dell'area riabilitativa ed il $22.70 \%$ dell'area assistenziale hanno denunciato minor piacere nello svolgimento del proprio lavoro durante il periodo della pandemia.

Al proposito citiamo il $33.14 \%$ dei terapisti occupazionali, il $31.88 \%$ dei tecnici della riabilitazione psichiatrica, il 28.63\% degli audioprotesisti ed il $28.26 \%$ dei terapisti della neuropsicomotricità dell'età evolutiva. (segue grafico). 
Figura 25: disinteresse al lavoro durante il periodo della pandemia suddiviso per professioni

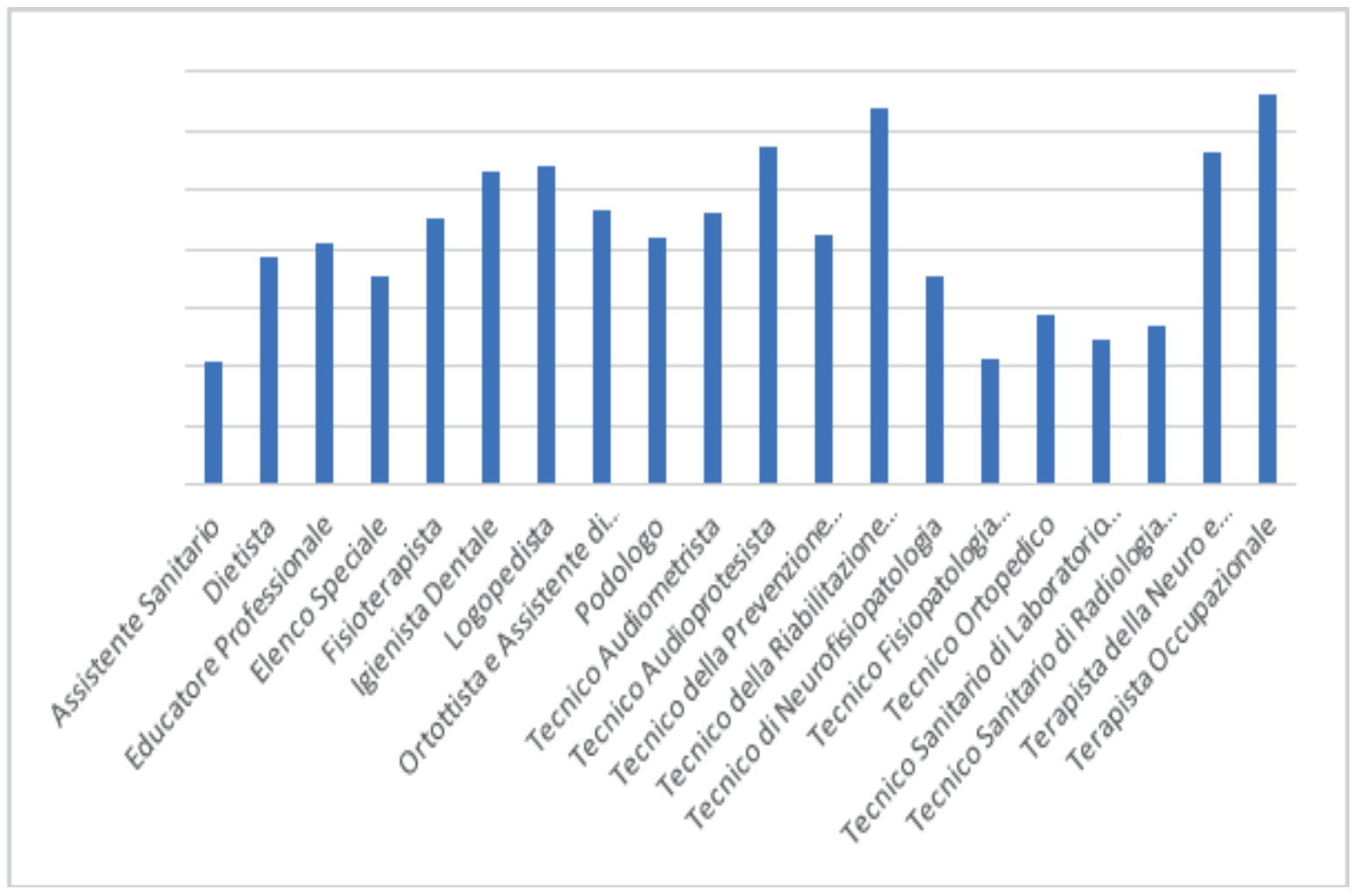

Ciò si segnala poiché, insieme ad altri elementi, potrebbe rappresentare un fattore di rischio.

Domanda 22. Ha vissuto altri eventi stressanti? (come problemi finanziari, cambiamenti sul lavoro, crisi relazionali nel lavoro o nella vita privata)

Questa domanda consente di analizzare ed evidenziare le correlazioni tra altre eventuali problematiche intercorse e la percezione dello stress derivato dalla pandemia.

Il $61,11 \%$ del campione ha risposto di aver vissuto contemporaneamente altri eventi critici e non si rilevano differenze sostanziali fra maschi e femmine nella risposta a tale quesito.

In particolare, sulla percentuale di professionisti che ha avuto colleghi che sono rimasti contagiati dal COVID-19 è elevata l'incidenza di un vissuto critico relativo a problematiche intercorse come espresso dal seguente grafico a torta. 
Figura 26: altri vissuti stressanti correlati al contagio dei colleghi

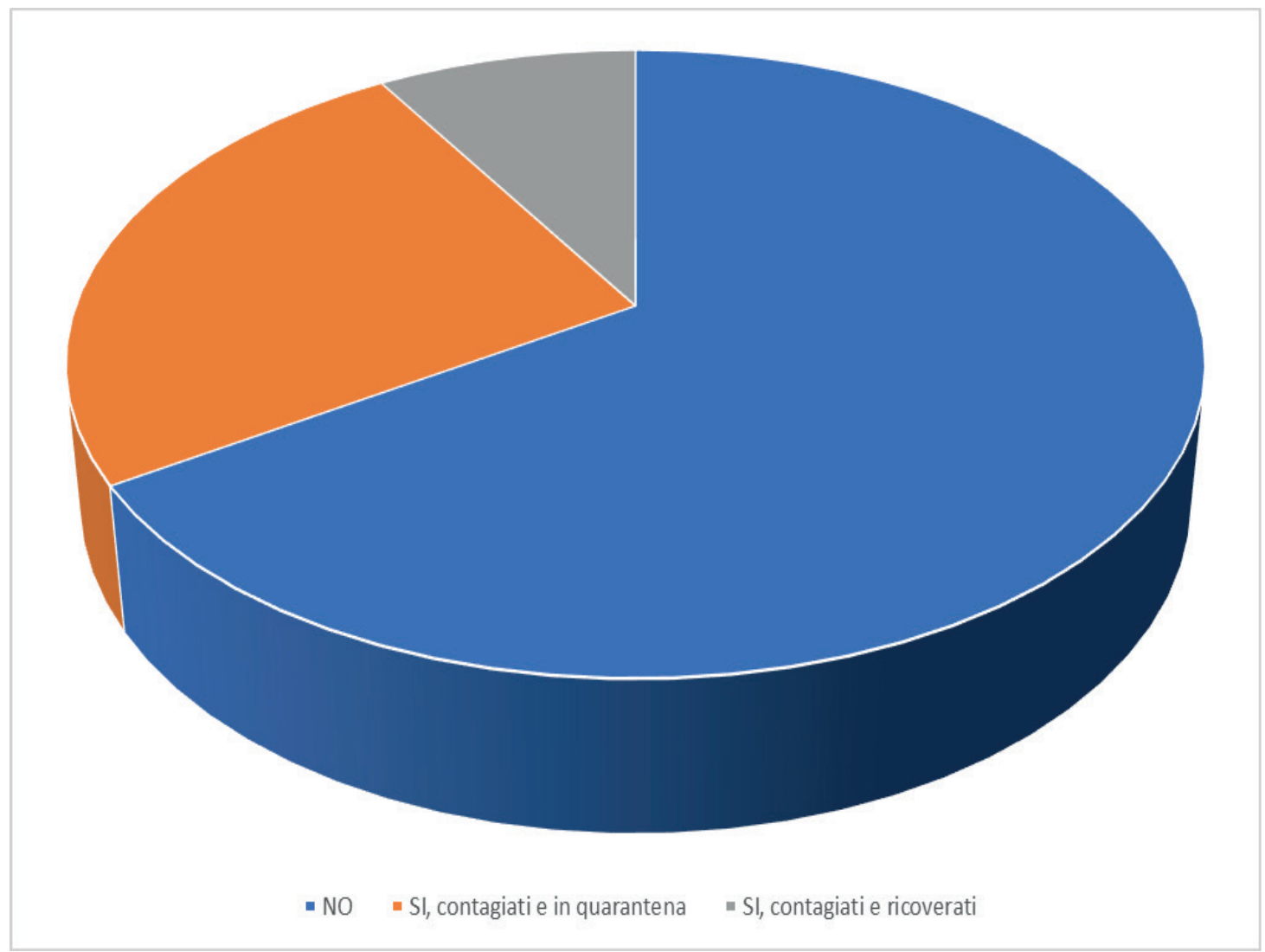

Le aree professionali che denunciano maggiormente il vissuto di eventi stressanti collaterali sono l'area assistenziale $(67,07 \%)$, la riabilitativa $(63,09 \%)$ ed i $(67,92 \%)$ professionisti appartenenti all'elenco speciale.

Domanda 23. Ha percepito o vissuto il mondo e le altre persone in modo diverso, tanto da sembrarle surreali o illusorie?

Circa il 51,41\% risponde di aver vissuto sensazioni disforiche rispetto alla percezione del mondo e delle altre persone, su tale percentuale incide maggiormente il campione femminile 
Figura 27: sensazioni disforiche rispetto alla percezione del mondo e delle altre persone da dati disaggregati per genere

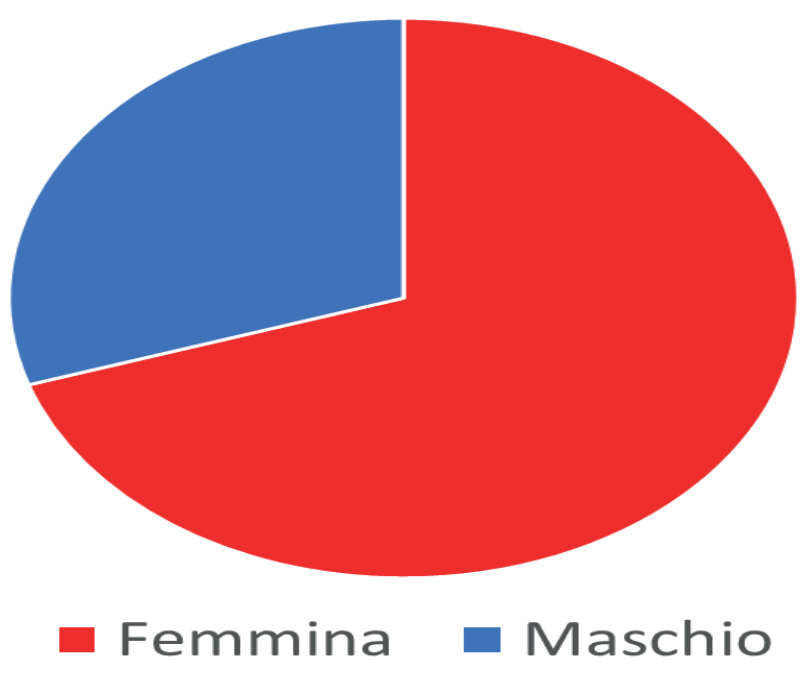

Fra le professioni, le aree più colpite da sensazioni disforiche, oltre l'area riabilitativa, che incide sulla percentuale totale anche per la numerosità del campione, emergono valori superiori al 53\% dei professionisti afferenti all'area tecnica diagnostica ed assistenziale (segue istogramma).

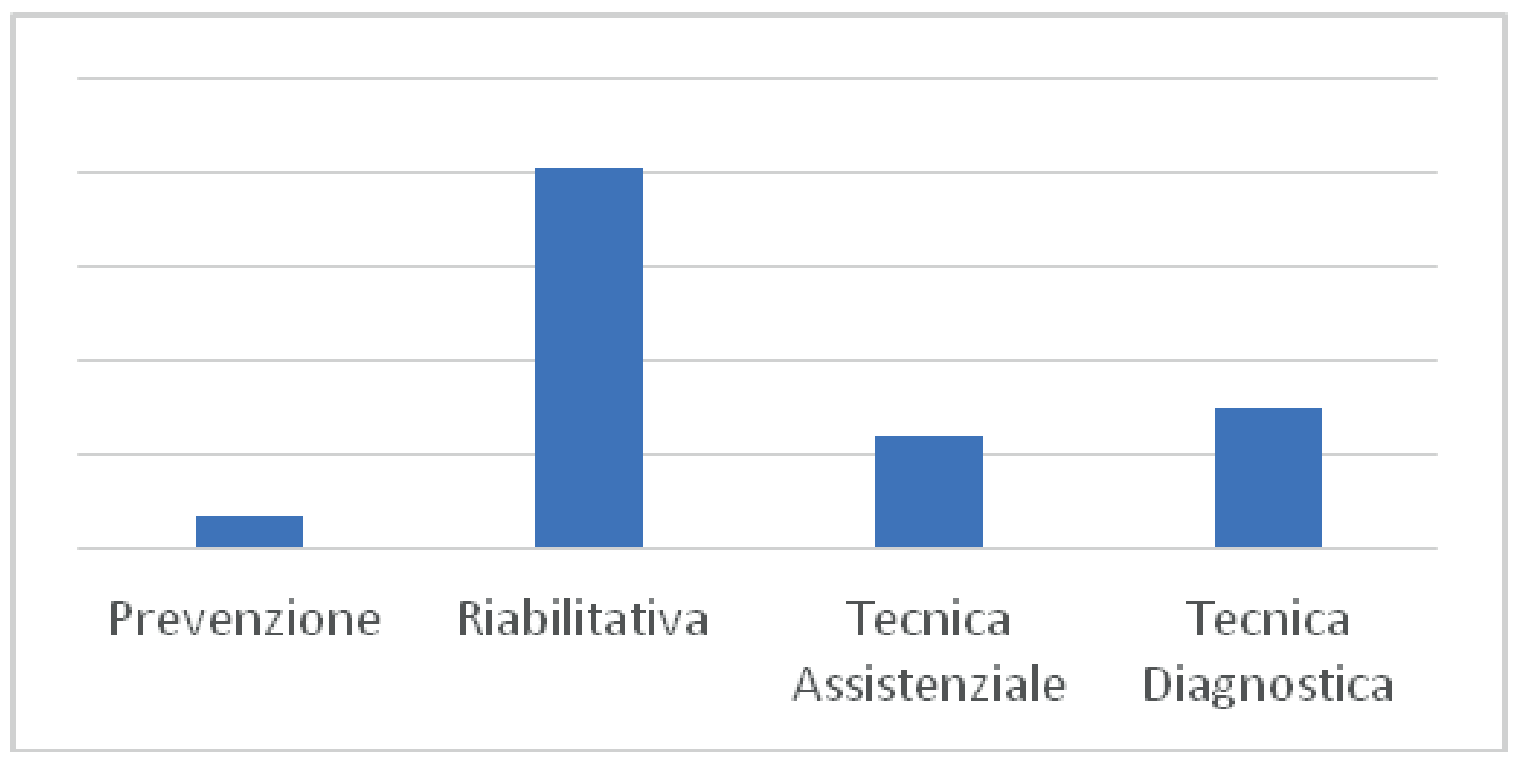

Figura 28: sensazioni disforiche da dati disaggregati per aree professionali 
Considerando poi le percentuali interne al campione, ben il $64.48 \%$ dei Tecnici Audioprotesisti denuncia di aver avuto vissuti disforici dell'ambiente esterno (segue grafico).

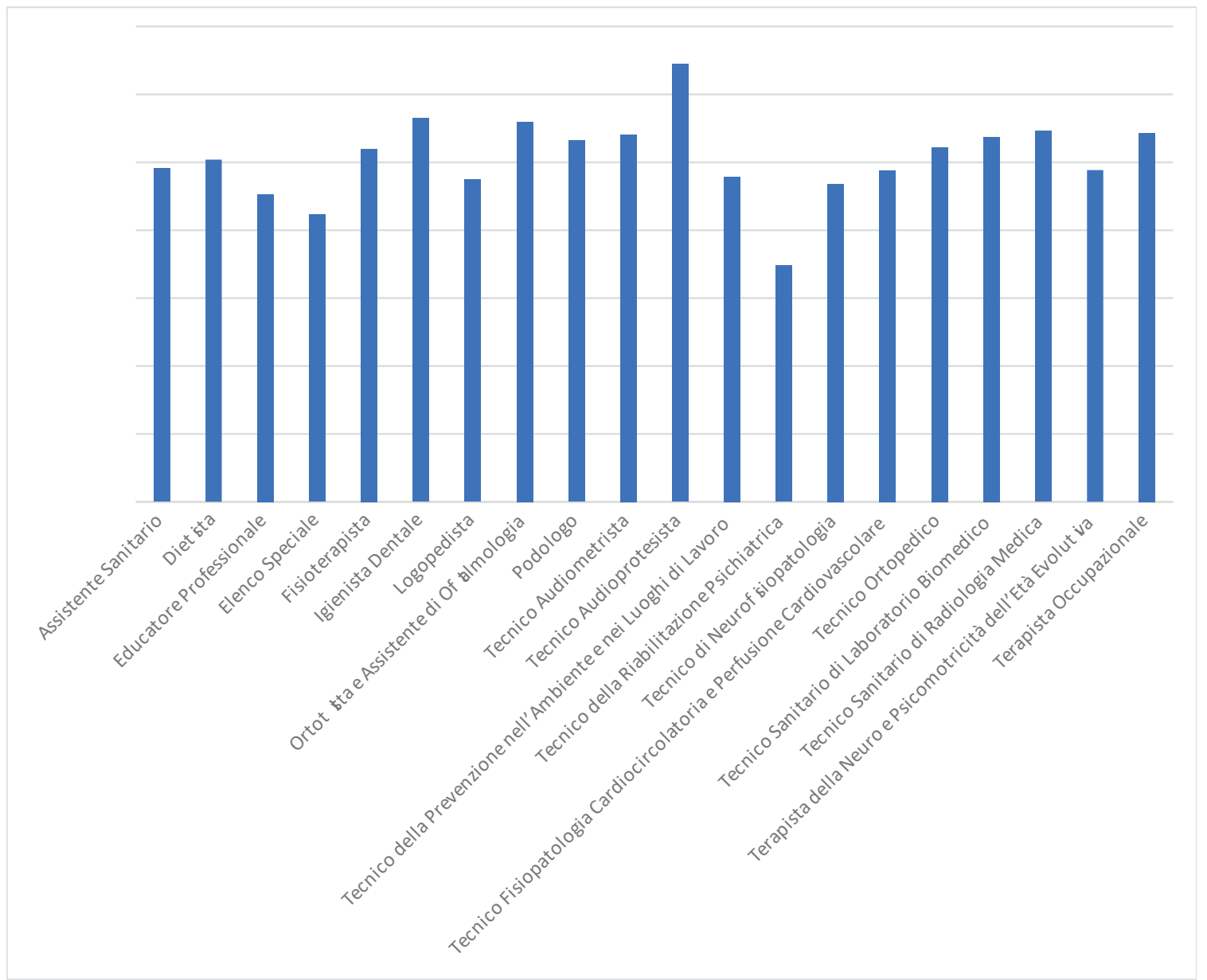

Figura 29: sensazioni disforiche per professioni

Infine, il $54.07 \%$ dei contagiati e più del $50 \%$ di coloro che hanno avuto colleghi contagiati da Covid-19 ha sofferto di tali fenomeni. 


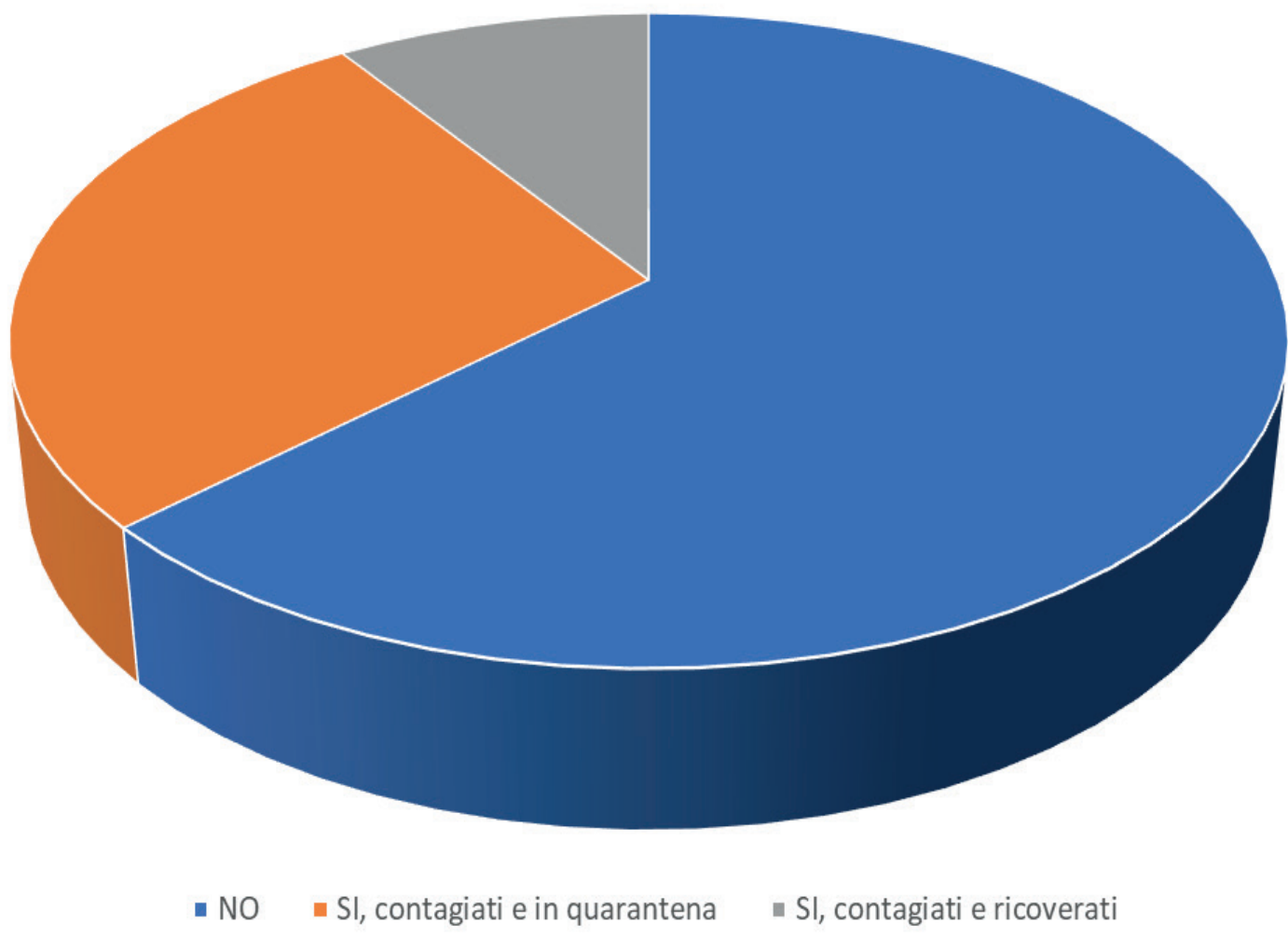

Figura 30: fenomeni disforici in professionisti che hanno avuto colleghi contagiati da Covid-19

\section{Domanda 24. Con che frequenza si è sentito/a nervoso/a o stressato/a}

Le domande sono state espresse in scala likert da 1 a 10 . Per semplificare la lettura dei dati sono stati aggregati i valori delle risposte da 6 a 10 per la valutazione della frequenza (medio/alta) di percezione di stress. Più del 77, 25\% degli intervistati si è sentito frequentemente nervoso/stressato, su questi dati si rileva l'incidenza soprattutto dell'area assistenziale e riabilitativa come espresso dal grafico.

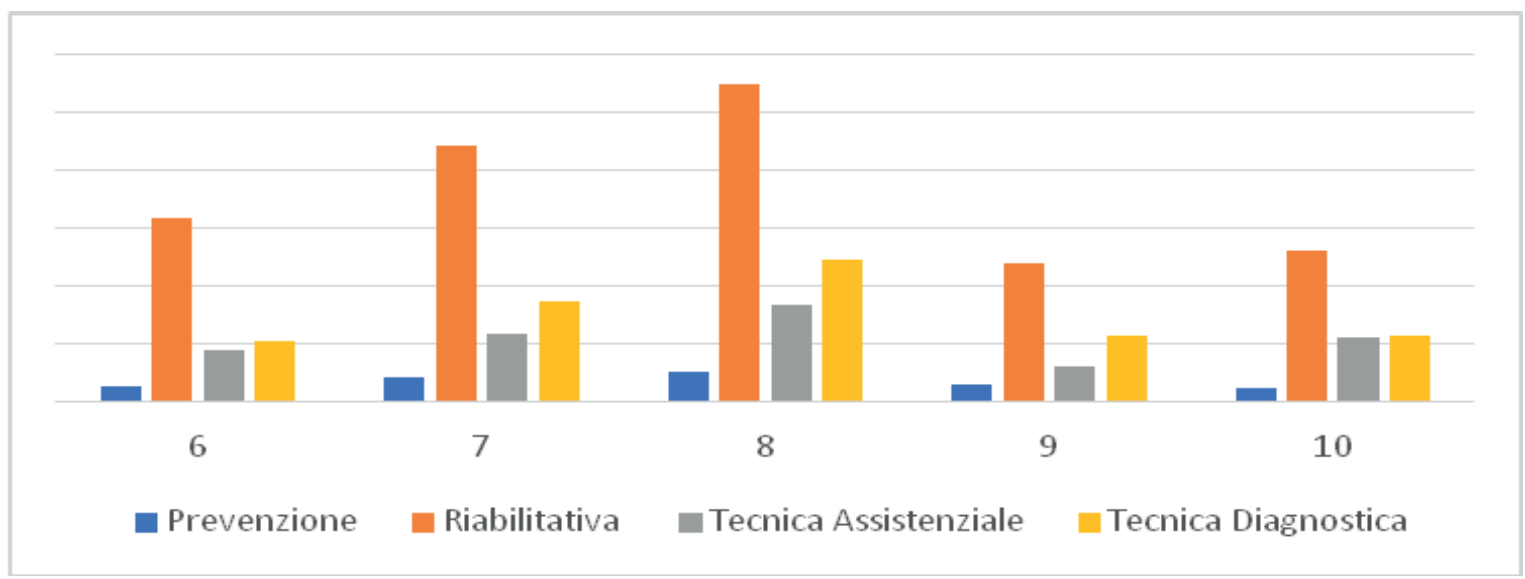

Figura 31: frequenza medio-alta di sensazione di nervosismo/stress per aree professionali 
Tali valori sono correlati positivamente al timore del contagio e/o all'esperienza di contagio personale o dei propri colleghi (vedi grafico seguente).

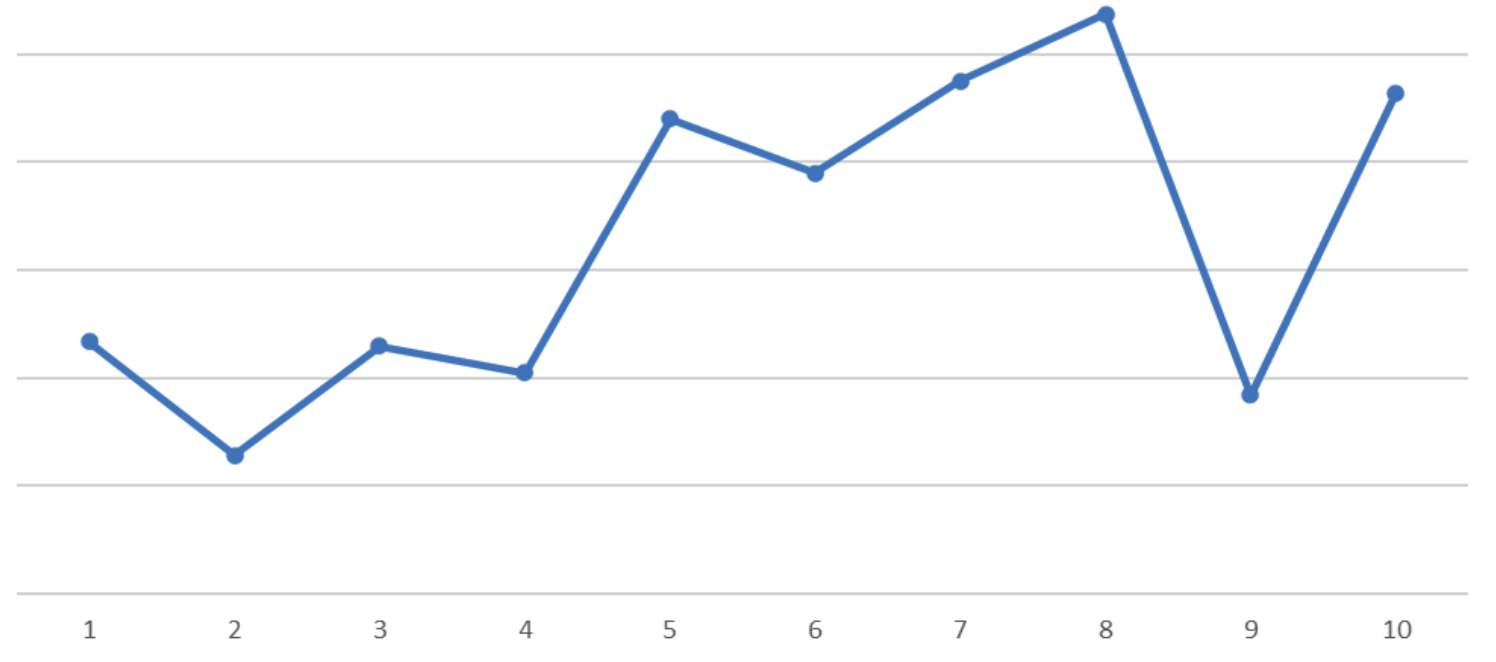

Figura 32: frequenza medio-alta di percezione di stress correlata alla esposizione al rischio di contagio del VIRUS

Fra le categorie che denunciano il maggiore livello di frequenza della sensazione di nervosismo ci sono fisioterapisti, tecnici sanitari di radiologia medica, tecnici sanitari di laboratorio biomedico, logopedisti, igienisti dentali la cui numerosità nella popolazione totale incide sulla valutazione finale di percezione di frequenza di stress per ciascuna professione.

Se consideriamo poi, le percentuali dei valori interni alle singole professioni emerge che la massima frequenza di sensazione di stress (livello 10 della scala likert) è stata vissuta dal $20.19 \%$ degli igienisti dentali, seguiti dal $19.68 \%$ dei tecnici audio protesisti; il valore più alto è rappresentato dal $30 \%$ dei tecnici audiometristi e dei terapisti occupazionali che esprimono una valutazione di frequenza di livello 8 nella scala likert.

Anche per questa domanda infine, la numerosità del campione femminile incide sulla valutazione finale con valori superiori al $70 \%$ per valutazioni di stress frequente considerando i valori dal $\mathbf{6}$ al $\mathbf{1 0}$ della scala likert come illustrato dal seguente istogramma. 


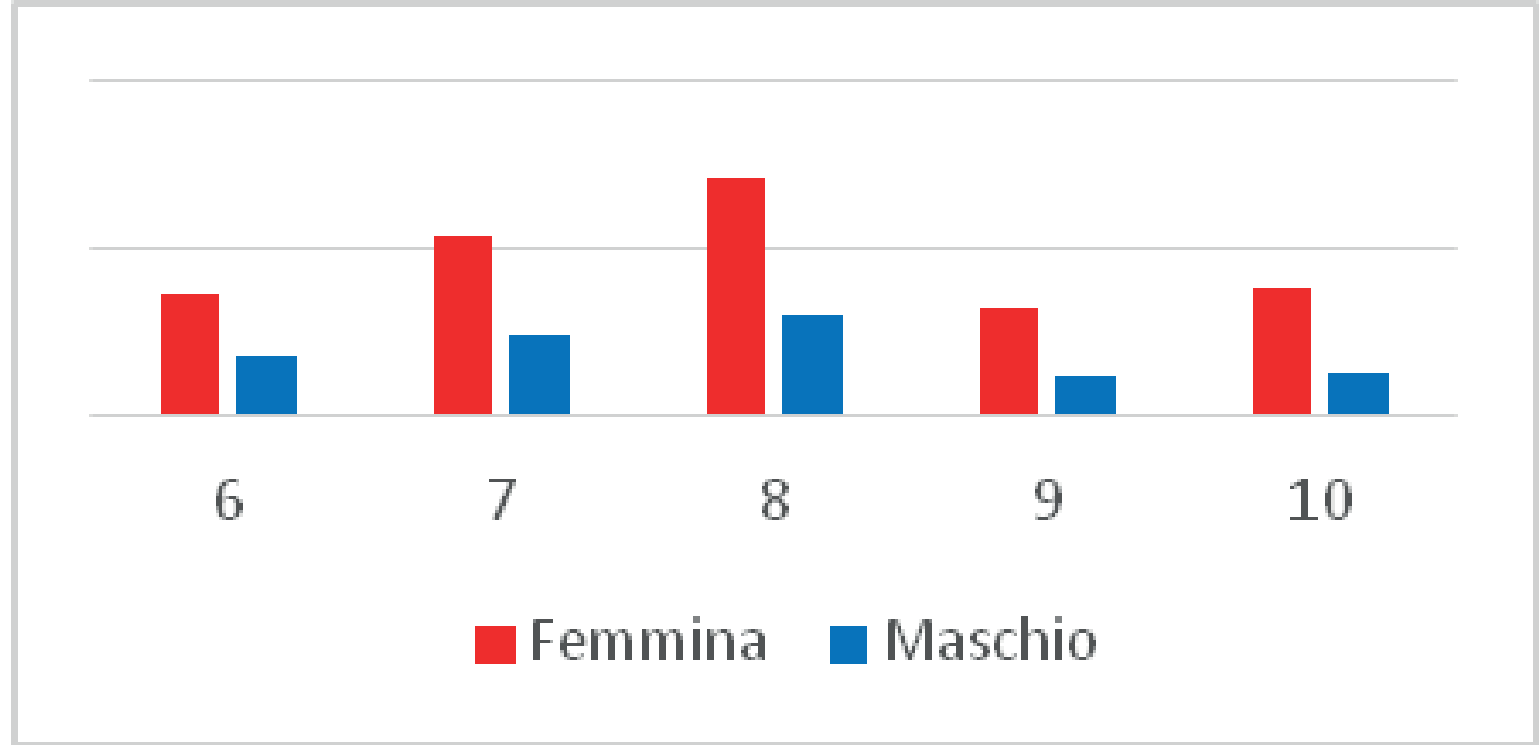

Figura 33: percezione medio-alta di stress da dati disaggregati per genere

Su questa percentuale ben il 12,85\% delle donne denuncia il livello 10, ovvero il massimo, di stress percepito.

$* * * * * * *$

La valutazione dei dati relativi alla percezione di stress dei professionisti intervistati, del loro stato d'animo, dell'auto-valutazione dell'efficacia e del grado d'interesse o disinteresse nello svolgere l'attività lavorativa durante l'emergenza pandemica, è un dato altamente pregnante nell'attuale realtà socio-lavorativa.

Infatti, tutti questi elementi che contribuiscono a disegnare un quadro relativo alla influenza della pandemia sulla percezione positiva/negativa del mondo e sulla motivazione al lavoro delle professioni intervistate.

Il timore o il contagio da COVID-19 ha registrato una correlazione positiva con la frequenza della percezione di nervosismo, con altri eventi stressanti e con fenomeni disforici; ciononostante globalmente la resilienza dei nostri operatori ha prevalso manifestandosi anche attraverso la percezione di utilità della propria professione. Questi dati suggeriscono che la "condivisione" può costituire un elemento di attivazione partecipativa che sostiene la motivazione al lavoro dei nostri professionisti in questa emergenza pandemica.

La pandemia da COVID-19 ha certo colpito tutti, ma ovviamente in modo diverso; in questo studio, fra gli operatori TSRM PSTRP, raccogliendo i dati disaggregati per sesso, nel modo di affrontare la situazione di stress emerge una differenza di genere: le donne intervistate denunciano un livello di stress più elevato e sensazioni disforiche in misura maggiore degli 
uomini e ciò va di pari passo ad una sensazione di minor utilità e piacere verso il proprio lavoro.

Le osservazioni derivanti da ricerche scientifiche accreditate indicano che rispetto alla popolazione generale, la prevalenza della depressione e la percezione di una scarsa salute generale è maggiore nelle donne rispetto ai uomini quando svolgono funzioni di CF (Caregiver Familiare), ovvero quando si prendono cura di familiari non autosufficienti o con patologie croniche invalidanti. In Italia, come nel resto del mondo, il $65 \%$ dei CF sono donne di età compresa tra i 45 e i 55 anni, che spesso svolgono anche un lavoro fuori casa.

I dati esaminati sono dunque in linea con quelli emergenti sul livello di stress registrato dalla popolazione femminile in Italia e nel mondo, visto il quadruplice ruolo di lavoratrice, madre, moglie, e spesso di CF dei propri familiari anziani.

Le differenze di genere si basano sia su caratteristiche biologiche, fisiche e fisiologiche, sia sul ruolo sociale, ovvero l'identità, l'espressione e il comportamento che la persona assume nel contesto socio-culturale in cui vive.

Le donne mostrano una minore resilienza rispetto agli uomini, a causa del fatto che la strategia femminile di risposta a situazioni di stress è legata all'emotività, mentre nell'uomo prevale una risposta pragmatica. Ma la capacità di reagire positivamente allo stress nelle donne potrebbe essere anche maggiormente influenzata dalla mancanza di un adeguato supporto sociale, sia informale che istituzionale. Nell'attuale situazione di emergenza da COVID-19, possiamo ragionevolmente ipotizzare che tale ulteriore stress percepito, sommato allo stress cronico e accompagnato dalla mancanza dei supporti di sostegno sociale e sanitario di cui normalmente si beneficia, possa portare a un peggioramento generale della qualità di vita, in particolare per le donne. Infatti, con l'emergenza della pandemia da COVID-19, in modo particolare le donne, hanno dovuto affrontare situazioni specifiche imprevedibili con un aggravio di stress.

Si sono aggiunte nuove problematiche come la presenza dei figli a casa per la chiusura delle scuole e la convivenza forzata in casa con i familiari, le attività di cura e assistenza del familiare non autosufficiente, magari usufruendo di spazi ristretti e per più ore del solito. Non meno importanti gli aspetti correlati al proprio lavoro, difficile da conciliare con le incombenze familiari, o al contrario la perdita del lavoro con l'incertezza del futuro lavorativo e una situazione di difficoltà economica e di esiguità di risorse per poter affrontare l'emergenza. 
Un'ulteriore problematica è rappresentata dalla sospensione a tempo indefinito dei supporti socio-sanitari come assistenza domiciliare, centro diurno e terapie.

Inoltre, l'operatore sanitario ha la preoccupazione di poter contagiare il familiare convivente, con l'eventuale prospettiva del ricovero ospedaliero o l'isolamento a casa, nonché del maggior rischio di esiti nefasti legati al COVID-19, ma anche la preoccupazione di ammalarsi lui stesso di COVID-19, di non poter più svolgere il proprio ruolo nella famiglia e nella società, senza preavviso. Si fa presente che circa 1'1\% degli intervistati non risponde neanche a tale domanda denunciando una necessità di riservatezza e forse il timore di essere discriminato in seguito alla malattia.

Tutti questi elementi possono costituire dunque un'ulteriore fonte di stress.

Non si possono tralasciare tali criticità, in quanto, seppur ogni individuo reagisca in maniera differente alle situazioni stressanti, quando si supera una certa soglia temporale o di intensità, lo stress può avere effetti negativi sulla salute. Ciò ci induce a riflettere sulla necessità emergente di supportare con strumenti psicologici adeguati le problematiche emerse dall'esame della resilienza specialmente di alcune figure professionali più colpite da tali vissuti e della popolazione femminile in generale, in quanto, fra l'altro, essa costituisce la maggioranza della popolazione dei professionisti afferenti all'Ordine dei TSRM PSTRP.

In conclusione, benché la sensazione di stress sia frequentemente percepita dai TSRM PSTRP intervistati, anche collegata ad altri eventi problematici intercorsi durante il periodo della pandemia, inducendo in più del $50 \%$ della popolazione totale fenomeni disforici, la grande maggioranza dei professionisti non perde l'interesse per la propria professione, sentendo utile il proprio lavoro.

Tali dati sostanziano cioè la necessità di un particolare approfondimento sull'incidenza degli eventi critici collaterali alla pandemia sulla motivazione al lavoro per individuare, laddove possibile, le necessarie azioni correttive.

Nonostante tutto, infatti, globalmente, la resilienza dei nostri operatori ha finora prevalso, ma ciò non deve farci dimenticare la necessità urgente di azioni a sostegno del benessere psicologico a carico delle professionalità maggiormente colpite da stress derivante dalla emergenza pandemica. 